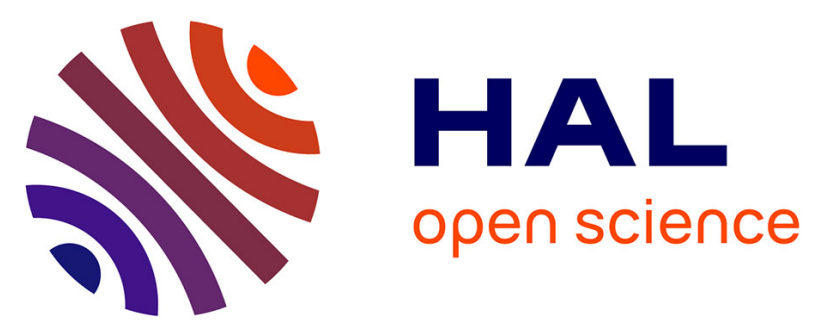

\title{
From finger friction and induced vibrations to brain activation: Tactile comparison between real and virtual textile fabrics.
}

\author{
Brigitte Camillieri, Marie-Ange Bueno, Benjamin Juan, Betty \\ Lemaire-Semail, Laurence Mouchnino, Marie Fabre
}

\section{To cite this version:}

Brigitte Camillieri, Marie-Ange Bueno, Benjamin Juan, Betty Lemaire-Semail, Laurence Mouchnino, et al.. From finger friction and induced vibrations to brain activation: Tactile comparison between real and virtual textile fabrics.. Tribology International, 2018, 126, pp.283-296. 10.1016/j.triboint.2018.05.031 . hal-01944349

\author{
HAL Id: hal-01944349 \\ https://hal.science/hal-01944349
}

Submitted on 16 Jun 2020

HAL is a multi-disciplinary open access archive for the deposit and dissemination of scientific research documents, whether they are published or not. The documents may come from teaching and research institutions in France or abroad, or from public or private research centers.
L'archive ouverte pluridisciplinaire HAL, est destinée au dépôt et à la diffusion de documents scientifiques de niveau recherche, publiés ou non, émanant des établissements d'enseignement et de recherche français ou étrangers, des laboratoires publics ou privés. 


\title{
From finger friction and induced vibrations to brain activation: tactile comparison between real and virtual textile fabrics
}

\author{
Brigitte CAMILLIERI ${ }^{1}$, Marie-Ange BUENO ${ }^{1 *}$, Marie FABRE $^{2}$, Benjamin JUAN ${ }^{2}$, \\ Betty LEMAIRE-SEMAIL ${ }^{3}$, Laurence MOUCHNINO ${ }^{2}$
}

${ }^{1}$ Univ. Haute Alsace, Laboratoire de Physique et Mécanique Textiles, École Nationale Supérieure d'Ingénieurs Sud-Alsace, Mulhouse, France.

${ }^{2}$ Aix-Marseille Univ, CNRS, LNC FR 3C 3512, Marseille, France.

${ }^{3}$ Univ. Lille, Arts et Métiers Paris Tech, Centrale Lille, HEI, EA 2697 - L2EP -

Lab. d'Electrotechnique et d'Electronique de Puissance, Lille, France

*Correspondence: Marie-Ange Bueno, marie-ange.bueno@uha.fr, Tel: +33(0)389 336320

\begin{abstract}
The objective is to compare the tactile rendering of real and virtual textile surfaces. A grooved woven (twill) and a hairy fabric (velvet) were studied. The virtual fabrics were simulated with a tactile device. The comparison was done by measuring the finger interaction in terms of coefficient of friction (COF) and induced vibrations, and brain activation by electroencephalography (EEG). EEG showed that the real and virtual twill fabrics are close, contrary to real and virtual velvets. The finger friction showed that for both fabrics the rendering of virtual compared to real fabrics is very good in terms of COF, low in terms of finger induced vibrations in high frequencies, but differs for the velvet texture for low frequencies.
\end{abstract}

Keywords: Tactile, friction, finger, textile, virtual surface, EEG. 


\section{INTRODUCTION}

The possibility to simulate the touch feeling of surfaces is of high importance for many applications: e-commerce for products in direct interaction with humans (garments, car upholstery and dashboard, furniture ...) [1], virtual prototyping as design assistance [2], and also tactile deficiency detection and patient rehabilitation.

In the textile field, tactile simulation could be used by the final consumer to choose a textile material sold through the internet $[1,3-5]$. In the near future, it might be common to have one's own 3D body shape [6], to choose a fabric in terms of colour, texture and drape, to choose a garment shape and to simulate individual avatars wearing virtual garments [2, 7]. In pursuing these goals it is therefore essential to improve the touch rendering of the virtual fabrics [8]. In this field, few papers report simulation of textile fabrics with a tactile device. The tactile device used can be a friction modulation device based on ultrasonic vibration [9] or an array of 256 pin-electrodes allowing lateral finger movement [10]. In both cases, the control signal is generated from the surface textile modelled by its surface microgeometry. Therefore, the adhesion or deformation of the surface, i.e. the friction behaviour, is not taken into account.

One's ability to perceive different fabrics involves both cortical and peripheral mechanisms. The tactile afferents from the finger signal the transformation of soft tissues that occurs when the fingers interact with objects and thus provide information about the physical properties of the fabrics and the contact between the fabric and the finger. The brain uses the tactile afferent information related for example to the friction between contacted fabrics and the digits to categorise the fabric. Categorisation is the process by which sensory stimuli are recognised, differentiated, and placed into groups. Through this cognitive process the physical properties of the stimuli are transformed into knowledge of the fabric under the digits. But it is not known how, or even whether, the perception of virtual stimuli is modified during movement exploration. 
The literature reported results about friction between human finger or skin and textile fabrics [11-15]. Most of them used the coefficient of friction (COF). Nevertheless it is known since more than an half century that the COF is necessary but not sufficient to characterise fabric touch [16-18], therefore it can be supposed it is not sufficient for simulating fabric touch. More recently, from the consideration of the duplex tactile theory of tactile texture perception, some studies consider finger induced vibrations from tactile surfaces [19-21]. For a given fabric a specific spectrum can be obtained $[19,20]$.

Few papers reported studies of fabric touch with electroencephalography (EEG) and none on virtual textures. The tactile comfort during clothing wear has been evaluated with EEG, and it was observed the higher the shirt mass density, the higher the energy percentages at both the left and right occipitalia [22]. Recently, the COF between human fingers and textile fabrics, induced vibrations from an artificial finger and perception in terms of different descriptors (rough-smooth, coarse-fine, complex-uniform and surface comfort), have been correlated with EEG results [23]. It is quite difficult to extract results in a textile material point of view because the textile surfaces used are not precisely described. Specifically the weave pattern is not indicated. Nevertheless, the descriptors used are linearly correlated with the COF which is probably due to the choice of the fabrics investigated. In fact, the most influential parameter is the size of the elementary mesh linked to the number of warp and weft yarns per centimetre and the yarn count. The silk fabric is probably the smoothest, and it reveals a higher real contact area. Moreover, the direction of movement, i.e. in the warp or weft direction, is not indicated. It seems the movement is anteroposterior.

In a previous study $[24,25]$, three very different fabrics have been simulated from a tactile stimulator named STIMTAC. The objective was to show if the human participants were able to associate the virtual fabric to the corresponding real fabric. The results obtained showed in $80 \%$ of cases a virtual fabric has been associated to the correct real fabric [24]. Nevertheless, the 
distance between the real and the virtual fabrics has not been evaluated. The goal of this paper is to compare finger behaviour and cortical responses during a tactile task in a lateral finger movement for real or virtual fabrics, in terms of finger friction, induced vibrations and brain activation measured with EEG. The idea is to use further the analysis of the differences between virtual and real surfaces to improve the design and control of the tactile simulators.

The paper is organised as following: first, the experimental apparatus and methods both for tribological and EEG measurements are described; then the results are shown, highlighting the differences between virtual and real surfaces for two kinds of fabrics. Last, the discussion gives a first analysis and explanation of these differences.

\section{MATERIALS AND METHODS}

\subsection{Real and virtual textile fabrics}

Two fabrics have been investigated: a twill woven fabric and a velvet knitted fabric. The twill fabric is obtained by interlacing two yarns in the plane of the fabric in two orthogonal directions. This fabric is rather compact with 44 warp and 37 weft threads per centimetre. The yarns consist of filaments ( $97 \%$ polyethylene terephthalate, i.e. PET, and 3\% elastane), therefore the surface hairiness is very weak. The yarn fineness is 26 tex $(1$ tex $=1 \mathrm{~g} / \mathrm{km})$. The intercrossing of the yarns generates a fabric with relief in the form of inclined ribs $(19.5$ ribs or grooves $/ \mathrm{cm})$ (Fig. 1a-b).

The second fabric is very hairy and is obtained by knitting a ground yarn (in PET) forming the knitted structure, with some acrylic fibres introduced in the ground structure during the loop formation in order to form bristles/plush yarns (Fig. 1c). The acrylic fibres are shaved at a fixed length when they are caught in the knitted structure. The released bristles make up the pile and

are in the form of fibre bundles held on one side of the structure. The bristles obtained are parallel and of equal length (about $2 \mathrm{~mm}$ ). For this fabric which will be named velvet 
afterwards, the pile has a preferred direction in which it lies down, as with the fur of an animal. This preferred direction is called the "along pile" direction while the opposite direction is the "against pile" direction.

The virtual textile fabrics are simulated from the tactile device STIMTAC from a method described elsewhere [24-26]. STIMTAC is a continuous tactile stimulator and looks like the touchpad of a laptop computer (Fig. 2). STIMTAC provides a constant stimulation all over the touched surface at a given time. It is based on the reduction of the COF which is obtained with ultrasonic vibrations $(30-40 \mathrm{kHz})$ of the touched plate forming an air gap acting like a lubricant. The frequency of vibration of the plate is too high to be perceptible by the human hand which cannot perceive vibrations higher than $1 \mathrm{kHz}[27,28]$. The measurement of the finger position allows to change the plate vibration amplitude, i.e. the COF, every $0.1 \mathrm{~s}(100 \mathrm{~Hz})$. The simulation protocol of the investigated fabrics, i.e. the twill and the velvet fabrics, has been described elsewhere $[24,25]$. The friction signal obtained from the considered fabrics and specific sliders has been recorded. The instantaneous COF is obtained for each surface and used for the command signal of STIMTAC for a given virtual fabric [29, 30]. The surface of the samples (real as virtual) was $80 \times 50 \mathrm{~mm}^{2}$.

\subsection{Participants and tasks}

Nine right-handed participants without any known neurological, physiological, cognitive and motor disorders ( 4 women and 5 men) participated in the experiment (28 to 57 years with an average of 44). All procedures performed were in accordance with the 1964 Helsinki declaration and its later amendments or comparable ethical standards. The participants gave informed consent and provided information about their date of birth. None of them had been subjected to a similar experiment before. 
Each participant was requested to follow the same experiment procedure during approximately 1.5 hours. This procedure was chronologically organised as follows. The subject washed and dried her/his hands. The experiment took place in a room whose atmosphere was conditioned $\left(20 \pm 2^{\circ} \mathrm{C}\right.$ and $65 \pm 5 \%$ of relative humidity). Participants were seated in front of the tribometer (see §2.3). To ensure a correct position and comfort, an adjustable support covered with a towel held the subject's right arm (Fig. 2a). Participants were asked to close their eyes upon receiving the verbal instructions on the nature of the upcoming task while a metronome with beats set at $1 \mathrm{~Hz}$ (60 beats/min) was played. The instructions indicated static or medio-lateral movement tasks for the different fabrics. In this task, the participants were asked to move back and forth during 32 seconds at the speed of the metronome and to focus on the material they were rubbing. They were instructed to move their finger at an inclination angle of 25 degrees (between the finger and the surface). The movement amplitude was set at $40 \mathrm{~mm}$, the mean velocity at 40 $\mathrm{mm} / \mathrm{s}$ and the normal force at $0.5 \mathrm{~N}$. Before the experimental session, a training session with the eyes opened was performed on a fabric different from those used in the experiment, allowing the participants to adjust the amplitude of the movement of his/her finger and the normal force through a visual feedback on a computer screen showing the applied load. In all movement tasks, the participants heard a $50 \mathrm{~ms}$ tone (i.e., go signal for starting movement execution) delivered 3 seconds after the onset of the recording session (Fig. 3).

Moreover a static control task was performed: the participants were instructed to remain still throughout the trials, with the finger on the investigated surface. For reasons of homogeneity, the same auditory cues (i.e., go signal and metronome beats) as in the movement tasks were also delivered.

Virtual and real fabrics were tested with a lateral finger movement. The twill fabric has ribs and the finger always moves perpendicular to the ribs. The velvet fabric has been tested with a finger movement along (i.e., rightward direction) and against (i.e., leftward direction) main pile 
directions (Fig. 1c). Therefore, four measurements have been processed for the real velvet and four for the virtual velvet, and the same for the twill, i.e. a total of sixteen measurements. Between each measurement, an operator put a new sample in a random order and placed the finger at the starting point.

\subsection{Tribological measurements: Finger friction and induced vibrations}

To measure the friction between the finger and the fabric, a three-axis load cell (model 3A6020N, Interface Inc., Scottsdale, Arizona) was used. It provided the components of the force exerted by the finger along three orthogonal axes (the vertical axis = normal force; the axes in the horizontal plane gave the tangential force). The real fabric or the STIMTAC were positioned directly on the load cell (Fig. 2b).

The data were acquired with Pulse software from Bruël \& Kjaer, and the forces were calculated by an Excel spreadsheet. The procedure to obtain the COF is summarised in Fig. 4. The tangential force was calculated from its components in the horizontal plane $\left(\mathrm{Ft}_{\mathrm{x}}\right.$ and $\left.\mathrm{Ft}_{\mathrm{y}}\right)$ which give the COF, ratio of the tangential force Ft to the normal force Fn. During a finger movement, the friction force, and therefore the $\mathrm{COF}$, is respectively positive for the rightward movement and negative for the leftward direction. The values in the transient (when reversing the direction of motion) are ignored. The COF values between a minimum value and a maximum value determined from the plot have been retained. The COF in each of the directions of movement of the finger was obtained, and then the mean value was considered.

The vertical vibrations of the finger were measured by an accelerometer (Piezoelectric Charge Accelerometer 4374 with a charge amplifier 2635 from Bruël \& Kjaer, Mennecy, France). It was stuck on the right forefinger at $3 \mathrm{~mm}$ above the nail.

The accelerometer signal is analysed in the frequency domain and the whole process by the spectrum analyser Pulse. The autospectrum is calculated; it is the average of several spectra, 
i.e. 10 spectra in this study. The root mean square of the acceleration is considered relative to frequency.

The parameter extracted from the autospectrum is the power $P$ for a frequency bandwidth:

$$
P(\Delta f)=\sqrt{\frac{\sum_{\Delta f} R M S(f)^{2}}{C}}
$$

with

$\mathrm{f}:$ the frequency in $\mathrm{Hz}$,

$\Delta \mathrm{f}$ : the considered frequency bandwidth,

RMS(f): the root mean square of the acceleration at the f frequency in $\mathrm{m} / \mathrm{s}^{2}$,

$\mathrm{C}$ : factor depending on the weighing window used, in this case it is a Hanning window and $\mathrm{C}=1.5$.

Whatever the fabric, twill or velvet, virtual or real and the participant, the total frequency bandwidth is taken from 0 to $1000 \mathrm{~Hz}$. Because the finger is sensitive between about 3 to $1000 \mathrm{~Hz}$ [27], the low frequencies under $3 \mathrm{~Hz}$ are not considered.

\subsection{Electroencephalography recordings and analysis}

Electroencephalographic (EEG) activity was recorded continuously from $64 \mathrm{Ag} / \mathrm{AgCl}$ surface electrodes embedded in an elastic cap (BioSemi ActiveTwo system, BioSemi, Netherlands). Specific to the BioSemi system, "ground" electrodes were replaced by Common Mode Sense active and Driven Right Leg passive electrodes. The signals were pre-amplified at the electrode sites and post-amplified with DC amplifiers, filtered on-line with a $0.16 \mathrm{~Hz}$ high pass filter (Actiview acquisition program) and digitised at a sampling rate of $1024 \mathrm{~Hz}$ and resampled at $1000 \mathrm{~Hz}$ offline.

EEG signals were obtained by averaging, for each participant and each task (static and lateral movement tasks) and condition (virtual and real velvet or twill), all epochs synchronised 
relative to the movement onset in the leftward direction. Forty leftward movements were averaged. The leftward direction was preferred because in active touch the human finger moves with the inner part of the finger (i.e., in a leftward direction for movement with the right hand) which is exquisitely sensitive in perceiving different materials. This was observed by the authors in different studies. The average amplitude of the 50-ms pre-epoch served as baseline. The neural sources of the exploring movement were estimated using the dynamical Statistical Parametric Mapping (dSPM) [31] implemented in the Brainstorm software [32] (freely available at http://neuroimage.usc.edu/brainstorm). The data from all sensors processed and averaged for each participant, condition and electrode were considered. The forward model was computed using a three-shell sphere boundary element model (BEM) on the anatomical MRI brain MNI Colin27 template (15000 vertices), a predominant volume conductor model [33, 34].

\subsection{Statistic data treatment}

All the tribological results are expressed as mean \pm one standard deviation. The data treatment has been done with the software XLSTAT. The objective was to compare two sets of data in order to know if they are extracted from the same population or not. In all the cases, the data from the two sets are obtained from the same participant, therefore they are paired. Firstly, each set of data has been verified to follow the normal law with the Shapiro-Wilk test ( $\mathrm{p}$-value>0.05). If the two sets follow the normal law, the variances were compared with the Fisher-Snedecor test (F-test). In all these cases for which the variances were not significantly different, the means have been compared with the Student's t-test for paired data. If one or both of the two sets don't verify the normal law, the Wilcoxon signed rank test for paired data has been used. In order to test the linear correlation between two sets of data, the Pearson's coefficient of correlation R is calculated, and its square $\mathrm{R}^{2}$, the coefficient of determination, is used in demonstrating the linear correlation's strength in terms of percentage. For EEG measurement, the paired t-test has been 
used for the statistical source estimation maps for contrasts for each fabric (velvet and twill) [real minus virtual].

\section{RESULTS}

\subsection{General comments on $\mathrm{COF}$ and induced vibrations}

For a given participant, the four measurements done are quite reproducible.

However, it is observed the COF varies substantially from person to person. This is in accordance with previous results obtained for both real textile surfaces [35] and virtual surfaces simulated by STIMTAC $[29,30]$. In fact, the COF between the finger and a surface depends on the hydrolipid film composition, in terms of water and lipid ratio, especially with a smooth surface as STIMTAC [29]. This variation cannot be attributed to the environment in terms of temperature and relative humidity because the measurements are done in controlled atmosphere (see section 2.2).

Moreover, for a given surface, some similarities can be identified between the autospectra obtained from the whole panel of participants.

For all the participants and for the real and virtual velvet fabrics, the interesting frequency bandwidths are from 3 to $100 \mathrm{~Hz}$ and from 100 to $400 \mathrm{~Hz}$ (Fig. 5). The real twill fabric gives two types of autospectra depending on the participant (Fig. 6a-b). The first type of autospectra (Fig. 6a) has two interesting bandwidths [3-200 Hz] and [200-400 Hz]. The second type presents a frequency lower than $100 \mathrm{~Hz}$ (Fig. 6b). For the virtual twill fabric (Fig. 6c), the autospectra present two interesting frequency bandwidths, i.e. [3-200 Hz] and [200-400 Hz].

For the twill woven fabric, the spatial period between the ribs is close to $0.5 \mathrm{~mm}$ (see $\S 2.1$ ), giving a frequency of around $80 \mathrm{~Hz}$. In most cases the peak frequency in the bandwidth [3$200 \mathrm{~Hz}$ ] has a maximum less than $100 \mathrm{~Hz}$, probably due to the fabric relief. For the velvet fabric, the specific spatial length is due to hair tuft with a value of around $1 \mathrm{~mm}$, giving a 
frequency of about $40 \mathrm{~Hz}$ which corresponds approximately to the max of the peak between [3$100 \mathrm{~Hz}]$. These results are in accordance with $[19,20]$.

\subsection{Comparison between real and virtual velvet fabrics}

The statistical analysis reveals the COF for virtual and real velvet can be considered to originate from the same population ( $p$-value $=0.10$ for $\alpha=0.05$ ). Fig. 7 highlights the correlation between virtual and real velvet depending on the participants. The coefficient $\mathrm{R}^{2}$ is 0.87 which is very good. However, for some participants it can be observed that with virtual velvet the standard deviation is higher than with real surfaces. Moreover, the range of COF is wider for virtual velvet with $[0.1,1.2]$ than for real velvet with $[0.4,0.9]$.

For the finger induced vibration analysis, for the different bandwidths [3-1000 Hz], [3-100 Hz] and $[100-400 \mathrm{~Hz}]$, the power data obtained for the real and the virtual velvet fabrics have been compared (Fig. 8). The powers for the frequencies [3-1000 Hz] and [3-100 Hz] can be considered to originate from the same population ( $\mathrm{p}$-value respectively 0.43 and 0.81 , for $\alpha=0.05$ ) for both real and virtual fabrics. Nevertheless, the coefficients $R^{2}$ are close to zero with 0.04 for $[3-1000 \mathrm{~Hz}]$ and 0.08 for $[3-100 \mathrm{~Hz}]$. On the contrary, for the powers for the frequencies [100-400 Hz] the p-value is close to zero ( 0.04 for $\alpha=0.05)$, indicating that the two distributions did not originate from the same population.

The powers in the two frequency bandwidths [3-100 Hz] and [100-400 Hz] have been compared for both real and virtual velvet fabrics (Fig. 9) to confirm that each bandwidth was independent and therefore can be processed separately in our analyses. As expected, there is no obvious correlation between these two bandwidths. The data range in the bandwidth [3-100 Hz] has the same width for both real and virtual fabrics and is around [0.2-0.8], but for [100$400 \mathrm{~Hz}$ ] the data range is wider for the virtual fabric than for the real velvet fabric. 
To highlight the possible difference in brain activity that leads to a bias in the perception of the fabric for the virtual velvet, the statistical source maps were computed for each task and fabric

(Fig. 10). The maps were previously averaged minus the static control task. For the velvet fabric, some differences between real and virtual fabrics were observed. The statistical source maps revealed that the activity of the left orbitofrontal cortex together with the left posterior parietal cortex (PPC) and the dorsolateral prefrontal cortices (dl-PFC) of both hemispheres were greater when participants moved their finger on the virtual fabric than on the real velvet fabric.

\subsection{Comparison between real and virtual twill fabrics}

The COF for virtual and real twill fabrics can be considered to originate from the same population ( $\mathrm{p}$-value $=0.10$ for $\alpha=0.05$ ), and $\mathrm{R}^{2}$ is 0.93 (Fig. 11). As for velvet, the range of both $\mathrm{COF}$ is wider for virtual than for real twill fabric.

For the finger induced vibration analysis, for the different bandwidths [3-1000 Hz], [3-200 Hz] and $[200-400 \mathrm{~Hz}]$, the power data obtained for the real and the virtual twill fabrics have been compared (Fig. 12). The powers for the frequencies [3-1000 Hz] and [3-200 Hz] can be considered to originate from the same population ( $p$-value respectively 1.0 and 0.73 for $\alpha=0.05$ ) for both real and virtual fabrics. The coefficients $\mathrm{R}^{2}$ are only average with 0.42 for [3-1000 Hz] and 0.50 for [3-200 Hz]. On the contrary, for the powers for [200-400 Hz] the p-value is close to zero $(0.001$ for $\alpha=0.05)$, indicating that the two distributions did not originate from the same population.

The powers in the two frequency bandwidths [3-200 Hz] and [200-400 Hz] have been compared for both real and virtual twill fabrics (Fig. 13) to confirm that each bandwidth was independent and therefore can be processed separately in our analyses. There is no correlation between these two bandwidths. 
The brain activity associated with a close perception for both real and virtual twill fabrics is shown in Fig. 14. The statistical source maps revealed that the activity of the left frontopolar PFC and the anterior premotor cortex were greater when participants moved on a virtual fabric than on the real twill.

\section{DISCUSSION}

The results obtained are synthesised in Table 1 .

Each surface can be considered to give its own signature in terms of COF and vibration as well as brain activity. These signatures could explain the way the sensory stimuli are categorised to belong to the same fabric or not by the participants.

First of all, in this study it is confirmed that the COF was not sufficient for simulating fabric touch. Indeed, the high COF correlations between the real and virtual fabrics during lateral movement (for the velvet, $\mathrm{R}^{2}=0.87$ and for the twill, $\mathrm{R}^{2}=0.93$ ) were associated with different signatures in terms of frequency bands and brain activity. But some distance between the real and the virtual fabrics reported in this study could account for differences in the perception of the virtual fabrics relative to the real ones. For the finger vibration induced from friction, the powers in the perception range of the finger $[3-1000 \mathrm{~Hz}]$ are considered to be extracted from the same population between the real and the virtual fabrics whatever the fabric, velvet ( $\mathrm{p}$-value of 0.43 ) or twill (p-value of 1.0). For the twill fabric, there is an average linear correlation between real and virtual fabrics $\left(R^{2}=0.42\right)$ which was not observed for the velvet $\left(R^{2}=0.04\right)$. Therefore, on the whole bandwidth, the power of the friction induced vibrations can be considered to be satisfactory for twill fabric and should be improved for velvet. However, an analysis on the whole frequency bandwidth is not sufficient. Some differences were highlighted with a deeper analysis from the identified frequency bandwidths for each fabric. Two frequency bands were reported for all the fabrics. In the lower range of frequencies ([3-100 Hz] and [3- 
$200 \mathrm{~Hz}]$ for the velvet and twill respectively), the powers for the real and the virtual fabrics were extracted from the same population as confirmed the p-values ( 0.81 and 0.73 for the velvet and twill respectively). The simulation at these frequencies can be considered as satisfactory to the exception that the correspondence between the real and the virtual for the velvet fabric failed to be relevant $\left(\mathrm{R}^{2}=0.08\right)$ as compared to the twill $\left(\mathrm{R}^{2}=0.50\right)$.

A striking result was observed for the highest frequency bandwidth $([100-400 \mathrm{~Hz}]$ or $[200-$ $400 \mathrm{~Hz}]$ for the velvet and twill respectively) in that the powers of the real and the virtual fabrics are not extracted from the same population ( $p$-values close to zero), likely due to the clear presence of this highest bandwidth for the virtual fabrics and not for the real ones (Fig. 5 and 6). These results show that the velvet and twill simulations have to be improved in the highest frequency bandwidths.

Overall the frequency band analysis pointed out the lower range of frequencies [3-100 Hz] in the velvet as a candidate for the wrong perception for the virtual velvet fabric. In fact, the virtual velvet was not categorised by the participants as being close to a velvet fabric. Indeed, the [3$100 \mathrm{~Hz}]$ induced vibrations when the finger interacts with the real or virtual fabric stimulated differently the tactile afferents that innervate the finger. Among the tactile afferents, the FA-II (fast-adapting type II) Meissner endings sensitive to dynamic skin deformation of relatively high frequency $(\sim 5-50 \mathrm{~Hz})$ and Pacinian endings extremely sensitive to mechanical transients and high frequency vibrations $(\sim 40-400 \mathrm{~Hz})$ could be stimulated by this [3-100 Hz] bandwidth propagating through biological tissues [36]. It can be noticed that the peak frequency [30$40 \mathrm{~Hz}$ ] observed in Fig. 5 is considered as the best frequency for Meissner endings and as the peripheral stimuli reach the cortical level [37].

The stimulation being different between the real and virtual velvet fabrics prompted the brain activity to encode the stimuli evoked by the virtual fabric as a novel texture (rather than to retrieve the velvet texture). In addition, the real and virtual velvets may have shown different 
compliance. Indeed, Condon et al. [38] have reported different sensitivity to surface compliance by tactile afferents in the human finger pad. SAI (Merkel endings) and FAI (Meissner endings) afferents appeared to be well suited to carry compliance information whereas FAII (Pacini endings) played a minor role. The grounds for this suggestion are twofold. When the difference was maximal between the real and the virtual fabrics, the left orbitofrontal cortex was more active for the virtual novel texture than for tactile exploration of the familiar velvet fabric. Indeed, Frey et al. [39] demonstrated a strong relationship between the orbitofrontal cortex and the attempt to encode tactile information which is consistent with the role of the orbitofrontal cortex for recognition memory. For instance, these authors showed a peak of increased activity in the orbitofrontal cortex when comparing (with positron emission tomography methods) the tactile exploration of novel stimuli from a related set of textures with familiar tactile stimuli in normal human subjects. The present findings in this study, together with results of Frey et al. [39], demonstrate that the orbitofrontal cortex is involved in the active encoding of novel tactile information. Together with the orbitofrontal activity, in the virtual tactile encoding condition, there was a selective increase of activity of the dl-PFC within the left hemisphere and in the right hemisphere as well. The dl-PFC activity may witness the monitoring and manipulation of actively maintained information for retrieval of similar texture information when facing novelty in the stimuli. This is in line with literature that has also suggested the role of the dl-PFC activity during working memory tasks (WM), a system that is used for temporary storage and manipulation of information and that is involved in many higher cognitive functions [40-42]. For instance Braver et al. [43] reported bilateral dl-PFC region, i.e. BA 46/9, activation during working memory (WM) but not during either long-term memory (LTM) encoding or retrieval. Besides, the increased activity of the left PPC when dealing with the virtual velvet new stimuli is in line with its critical role in specific processing of the perceived kinaesthetic cues during action-related somatosensory information processing [44]. The frontoparietal network observed 
here for the virtual velvet fabric is in agreement with Cavada and Goldman-Rakic [45] who showed in monkeys that all frontoparietal connections are reciprocal, and although they are most prominent within a hemisphere, notable interhemispheric connections are also present. The present neuroimaging data point to the conclusion that tactile information from the virtual velvet fabric deviates significantly from expectations and therefore is considered as a novel fabric.

By contrast to the velvet fabric, the high congruence in [3-200 Hz] frequency bands for the twill between real and virtual textures seems to favour perceptual categorisation and judgements. Indeed, for all the participants the sensory representation of the virtual fabric was close to the real one. The observed increased activity for the virtual twill fabric as compared to the real fabric in the left frontopolar PFC and anterior premotor cortex is in line with brain activation reported during perceptual judgement. The conversion of a sensory signal from the periphery and reaching the primary somatosensory cortex into perceptual categorisation as here with twill, was reported in the literature to involve premotor areas of the frontal lobe [46]. For instance, these authors showed in monkeys that the activity arising from the somatosensory cortex during vibrotactile stimuli gradually relates more to the perceptual reports as it reaches the premotor areas. Indeed, they showed a correlation between neuronal responses of neurons within ventral, dorsal and medial premotor areas and perceptual judgements during detection tasks. Frontopolar activity also reported in the current study has been previously associated with retrieval from long-term memory [47]. However, Braver et al. [43] failed to find frontopolar regions to be selectively engaged by retrieval. Nevertheless, the crucial role of the PFC during tactile memory processing is well established [48]. 


\section{CONCLUSION}

In this study the COF and the friction induced vibrations from the finger and different surfaces are studied. The surfaces investigated are real or virtual velvet and twill fabrics. The virtual fabrics are simulated with a tactile device. The velvet fabric presents a regular hairy surface, and the twill fabric has a grooved surface. The real and virtual fabrics are compared in terms of the finger response to friction, i.e. coefficient of friction and induced vibrations, and brain activation, by electroencephalography.

The brain activation comparing real and virtual fabrics concerned different areas for twill and for velvet fabrics. In fact, between real and virtual twill fabrics the brain activation presents similarities but for the velvet texture there are important differences. The results show the rendering of virtual fabrics is good in terms of COF. This confirms the fact, well known in the literature, that the $\mathrm{COF}$ is not sufficient to describe the tactile rendering of textile fabrics. A deeper analysis in terms of finger induced vibrations shows some similarities and differences between real and virtual surfaces which can explain the difference of rendering between real and virtual textures for velvet and twill fabrics. In fact, the rendering before 100 or $200 \mathrm{~Hz}$ is satisfactory for twill and far less for velvet fabric. Up to these frequencies the fabric simulations have to be improved for both fabrics. Therefore, it can be concluded that the difference in vibrotactile stimulation in a specific bandwidth, in the range of sensitivity of both Meissner and Pacinian endings, prompts the brain to change the cortical areas that are activated. For the virtual velvet, areas are required in encoding of a novel texture, and for the virtual twill, areas are involved in the retrieval of perceptual categorisation. 


\section{Acknowledgements}

The authors thank the CNRS for the financial support of the DISREMO project. The authors are deeply grateful to all the participants from the University of Haute Alsace who participated and gave their time freely.

\section{Ethical statements}

The authors declare that they have no conflict of interest.

All procedures performed in studies involving human participants were carried out in accordance with the 1964 Helsinki declaration and its later amendments or comparable ethical standards.

Informed consent was obtained from all individual participants included in the study. 


\section{References}

[1] Khakimdjanova L, Park J. Online visual merchandising practice of apparel e-merchants. Journal of Retailing and Comsumer Services. 2005;12:307-18.

[2] Fontana M, Rizzi C, Cugini U. Physics-based Modelling and Simulation of Functional Cloth for Virtual Prototyping Applications. In: G. Elber NP, P. Brunet, editor. ACM Symposium on Solid Modeling and Applications2004.

[3] Bingi P, Mir A, Khamalah J. The Challenges Facing Global E-commerce: A Multidimensional Perspective. Information Systems Management Journal. 2000;17:26-34.

[4] Peck J, Childers TL. To Have and To Hold:The Influence of Haptic Information on Product Judgments. Journal of Marketing. 2003;67:35-48.

[5] Varadarajan PR, Yadav MS. Marketing Strategy and the Internet: An Organizing Framework. Journal of the Academy of Marketing Science. 2002;30:296-313.

[6] Loker S, Ashdown S, Carnrite E. Dress in the Third Dimension: Online Interactivity and Its New Horizons. Clothing and Textiles Research Journal. 2008;26:164-76.

[7] Luginbühl T, Delattre L, Gagalowicz A. Towards the Automatic Generation of 3D Photo-Realistic Avatars Using 3D Scanned Data. Computer Science. 2011;6930:192-203.

[8] Blazquez Cano M, Perry P, Ashman R, Waite K. The influence of image interactivity upon user engagement when using mobile touch screens. Computers in Human Behavior. 2017;77:406-12.

[9] Maeno T, Otokawa K, Konyo M. Tactile Display of Surface Texture by use of Amplitude Modulation of Ultrasonic Vibration. IEEE Ultrasonics Symposium2006. p. 625.

[10] Peruzzini M, Germani M, Mengoni M. Electro-tactile device for texture simulation. IEEE/ASME International Conference on Mechatronics and Embedded Systems and Applications (MESA)2012. p. 178-83.

[11] Darden MA, Schwartz CJ. Investigation of skin tribology and its effects on the tactile attributes of polymer fabrics. Wear. 2009;267:1289-94.

[12] Derler S, Schrade U, Gerhardt LC. Tribology of human skin and mechanical skin equivalents in contact with textiles. Wear. 2007;263:1112-6.

[13] Gerhardt L-C, Strässle V, Lenz A, Spencer ND, Derler S. Influence of epidermal hydration on the friction of human skin against textiles. J R Soc Interface. 2008;5:1317-28.

[14] Kenins P. Influence of Fiber Type and Moisture on Measured Fabric-to-Skin Friction. Text Res J. 1994;64:722-8.

[15] Ramalho A, Szekeres P, Fernandes E. Friction and tactile perception of textiles fabrics. Tribol Int. 2013;63:29-33.

[16] Morrow JA. The frictional properties of cotton materials. The Journal of the Textile Institute. 1931:T425-T40.

[17] Dreby EC. A Friction Meter for Determining the Coefficient of Kinetic Friction of Fabrics. Journal of Research of the National Bureau of Standards. 1943;31:237-46.

[18] Hoffman RM, Beste LF. Some Relations of Fiber Properties to Fabric Hand. Text Res J. 1951;21:66-77.

[19] Fagiani R, Massi F, Chatelet E, Berthier Y, Akay A. Tactile perception by friction induced vibrations. Tribol Int. 2011;44:1100-10.

[20] Fagiani R, Massi F, Chatelet E, Costes J-P, Berthier Y. Contact of a finger on rigid surfaces and textiles: Friction coefficient and induced vibrations. Tribol Lett. 2012;48:145-58.

[21] Zahouani H, Mezghani S, Vargiolu R, Hoc T, El Mansori M. Effect of roughness on vibration of human finger during a friction test. Wear. 2013;301:343-52.

[22] Wang Y, Wang Y, Zhao M, Yu M, Li J. Experimental Study of Clothing Tactile Comfort Based on Electro-neurophysiology. FIBRES \& TEXTILES in Eastern Europe. 2014;22:102-6.

[23] Chen S, Ge S. Experimental research on the tactile perception from fingertip skin friction. Wear. 2017;376-377:305-14.

[24] Ben Messaoud W. Design and Control of a Tactile Stimulator for Real Texture Simulation: Application to Textile Fabrics [PhD thesis]. Lille: Université de Lille 1; 2016.

[25] Ben Messaoud W, Bueno M-A, Lemaire-Semail B. Textile Fabrics' Texture: From Multi-level Feature Extraction to Tactile Simulation. In: Bello F, Kajimoto H, Visell Y, editors. Haptics: Perception, 
Devices, Control, and Applications: 10th International Conference, EuroHaptics. London, UK,: Springer International Publishing; 2016. p. 294-303.

[26] Bueno M-A, Lemaire-Semail B, Amberg M, Giraud F. Pile surface tactile simulation: role of the slider shape, texture close to fingerprints and the joint-stiffness. Tribol Lett. 2015;59:1-12.

[27] Darian-Smith I. Ch 17 : The sense of touch: Performance and peripheral neural process. In: J.D.Mountcastle B, editor. Handbook of Physiology. Baltimore: William and Wilkins; 1984. p. 739-88.

[28] Morley JW, Rowe MJ. Perceived pith of vibrotactile stimuli: Effects of vibration amplitude, and implications for vibration frequency coding. Journal of Psychology. 1990;431:403-16.

[29] Cornuault P-H, Carpentier L, Bueno M-A, Cote J-M, Monteil G. Influence of the physicochemical, mechanical and morphological fingerpad's properties on the frictional distinction of sticky/slippery surfaces. J R Soc Interface. 2015;12:20150495 (11 pages).

[30] Ben Messaoud W, Bueno M-A, Lemaire-Semail B. Relation between human perceived friction and finger friction characteristics. Tribol Int. 2016;98:261-9.

[31] Dale AM, Liu AK, Fischl BR, Buckner RL, Belliveau JW, Lewine JD, et al. Dynamic Statistical Parametric Mapping: Combining fMRI and MEG for High-Resolution Imaging of Cortical Activity. Neuron. 2000;26:55-67.

[32] Tadel F, Baillet S, Mosher JC, Pantazis D, Leahy RM. Brainstorm: a user-friendly application for MEG/EEG analysis. Comput. Intell. Neurosci. 879716. Computational Intelligence and Neuroscience. 2011;2011:13 pages.

[33] Huang Y, Parra LC, Haufe S. The New York Head-A precise standardized volume conductor model for EEG source localization and tES targeting. NeuroImage. 2016;140:150-62.

[34] Mosher JC, Leahy RM, Lewis PS. EEG and MEG: forward solutions for inverse methods. IEEE transactions on bio-medical engineering. 1999;46:245-59.

[35] Camillieri B, Bueno M-A. Artificial finger design for investigating the tactile friction of textile surfaces. Tribol Int. 2017;109:274-84.

[36] Johansson RS, Flanagan JR. Coding and use of tactile signals from the fingertips in object manipulation tasks. Nature Reviews Neuroscience. 2009;10:345.

[37] Mountcastle VB, Talbot WH, Sakata H, Hyvärinen J. Cortical neuronal mechanisms in fluttervibration studied in unanesthetized monkeys. Neuronal periodicity and frequency discrimination. J Neurophysiol. 1969;32:452-84.

[38] Condon M, Birznieks I, Hudson K, Chelvanayagam DK, Mahns D, Olausson H, et al. Differential sensitivity to surface compliance by tactile afferents in the human finger pad. J Neurophysiol. 2014;111:1308-17.

[39] Frey S, Zlatkina V, Petrides M. Encoding touch and the orbitofrontal cortex. Human Brain Mapping. 2008;30:650-9.

[40] D'Esposito M, Ballard D, Aguirre GK, Zarahn E. Human Prefrontal Cortex Is Not Specific for Working Memory: A Functional MRI Study. NeuroImage. 1998;8:274-82.

[41] Owen AM. The Functional Organization of Working Memory Processes Within Human Lateral Frontal Cortex: The Contribution of Functional Neuroimaging. European Journal of Neuroscience. 1997;9:1329-39.

[42] Smith EE, Jonides J. Storage and Executive Processes in the Frontal Lobes. Science. 1999;283:1657-61.

[43] Braver TS, Barch DM, Kelley WM, Buckner RL, Cohen NJ, Miezin FM, et al. Direct Comparison of Prefrontal Cortex Regions Engaged by Working and Long-Term Memory Tasks. NeuroImage. 2001;14:48-59.

[44] Hartmann S, Missimer JH, Stoeckel C, Abela E, Shah J, Seitz RJ, et al. Functional Connectivity in Tactile Object Discrimination-A Principal Component Analysis of an Event Related fMRI-Study. PLoS ONE. 2008;3:e3831.

[45] Cavada C, Goldman-Rakic PS. Posterior parietal cortex in rhesus monkey: II. Evidence for segregated corticocortical networks linking sensory and limbic areas with the frontal lobe. The Journal of Comparative Neurology. 1989;287:422-45.

[46] de Lafuente V, Romo R. Neural correlate of subjective sensory experience gradually builds up across cortical areas. Proceedings of the National Academy of Sciences. 2006;103:14266-71.

[47] Lepage M, Ghaffar O, Nyberg L, Tulving E. Prefrontal cortex and episodic memory retrieval mode. Proceedings of the National Academy of Sciences. 2000;97:506-11. 
[48] Romo R, Salinas E. Flutter Discrimination: neural codes, perception, memory and decision making. Nature Reviews Neuroscience. 2003;4:203.

\section{List of figures:}

Figure 1: Investigated surfaces a) 2/1 twill, b) twill with a dashed line on one rib (the arrow materialising the direction of friction) and c) velvet fabric.

Figure 2: a) Participant during an experiment and b) an index finger equipped with the accelerometer during a tactile task with STIMTAC fixed on the three-axis load cell.

Figure 3: Tangential force $(\mathrm{N})$ during the back and forth lateral movement of $40 \mathrm{~mm}$ in each direction. The participants were asked move continuously during 25 seconds. At the beginning of the recording session, the participant was at rest during 3 seconds until an auditory cue (go signal) triggered movement execution. The lateral movement started towards the right side for all participants. $\mathrm{t} 1$ was considered as the onset of the leftward movement.

Figure 4: Procedure to obtain the coefficient of friction (case of the real twill for one subject):

a) $\mathrm{Ft}_{\mathrm{x}}$ and b) $\mathrm{Ft}_{\mathrm{y}}$ components of the tangential force, c) tangential force $\mathrm{Ft}$, d) normal force $\mathrm{Fn}$, e) $\mathrm{COF}$ with positive values when the finger moves rightward and negative values for leftward, f) positive COF in the two directions of finger movement (the horizontal lines are the upper and lower limits chosen for the $\mathrm{COF}$ ), g) $\mathrm{COF}$ after suppression of the values due to the transient (reversal of the direction of movement).

Figure 5: Typical acceleration autospectra obtained from a) the real and b) the virtual velvet fabrics.

Figure 6: Typical acceleration autospectra obtained from the twill fabric a) and b) with the real fabric and c) with the virtual twill fabrics.

Figure 7: Coefficients of friction of real and virtual velvet fabrics. A dot corresponds to a participant. The black plain line is the line $y=x$. The closer a point to this line, the better is the correspondence between real and virtual fabrics. 
Figure 8: Power of the acceleration from a) 3 to $1000 \mathrm{~Hz}$, b) 3 to $100 \mathrm{~Hz}$ and c) 100 to $400 \mathrm{~Hz}$ for real and virtual velvet fabrics. A dot corresponds to a participant. The black plain line is the line $y=x$. The closer a point to this line, the better is the correspondence between real and virtual fabrics.

Figure 9: Power from 100 to $400 \mathrm{~Hz}$ relative to power from 3 to $100 \mathrm{~Hz}$ for both real and virtual velvet. A dot corresponds to a participant.

Figure 10: Statistical source estimation maps for real vs virtual velvet fabrics contrast. Significant $t$-values $(\mathrm{p} \leq 0.05, \mathrm{n}=9$ participants $)$ of the source localisation during leftward movements $(\mathrm{n}=40)$.

Figure 11: Mean coefficient of friction of real and virtual twill fabrics. A dot corresponds to a participant. The dotted line is the least squares line. The plain line is the line $y=x$. The closer a point to this line, the better is the correspondence between real and virtual fabrics.

Figure 12: Power of the acceleration from a) 3 to $1000 \mathrm{~Hz}$, b) 3 to $200 \mathrm{~Hz}$ and c) 200 to $400 \mathrm{~Hz}$ for real and virtual velvet fabrics. A dot corresponds to a participant. The dotted line is the least squares line. The black line is the line $y=x$. The closer a point to this line, the better is the correspondence between real and virtual fabrics.

Figure 13: Power from 200 to $400 \mathrm{~Hz}$ relative to power from 3 to $200 \mathrm{~Hz}$ for both real and virtual twill fabrics. A dot corresponds to a participant.

Figure 14: Statistical source estimation maps for real vs virtual twill fabrics contrast. Significant t-values $(\mathrm{p} \leq 0.05, \mathrm{n}=9$ participants) of the source localisation during leftward movements $(n=40)$.

Table 1: Synthesis of the obtained results in terms of COF, finger induced vibrations and brain activation. 
Figure 1

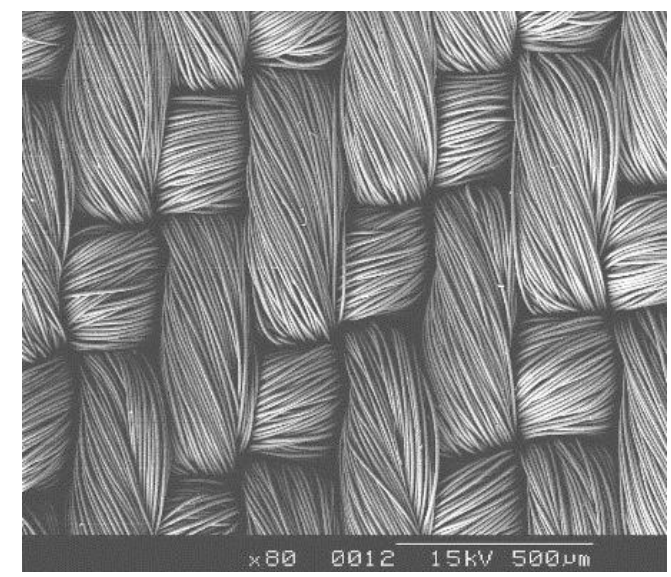

a)

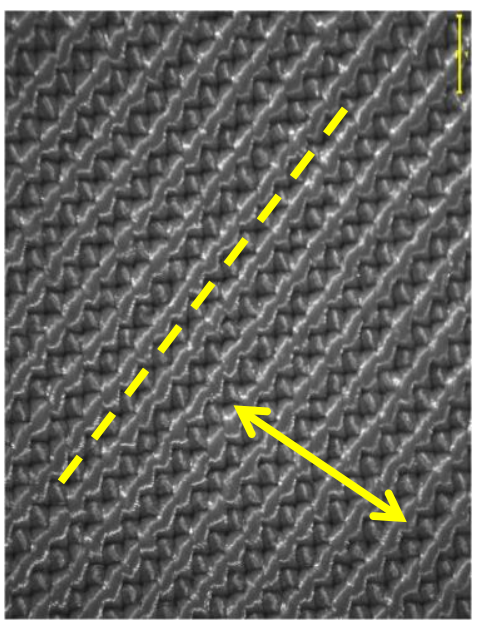

b)

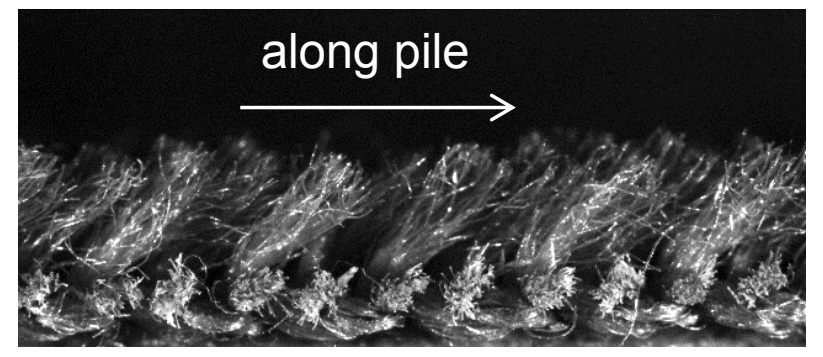

c) 
Figure 2

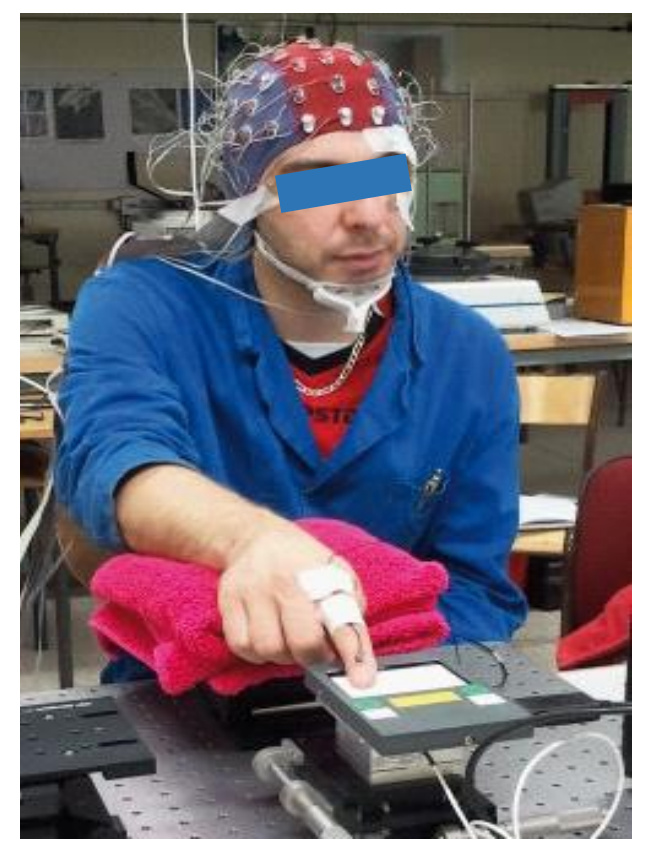

a)

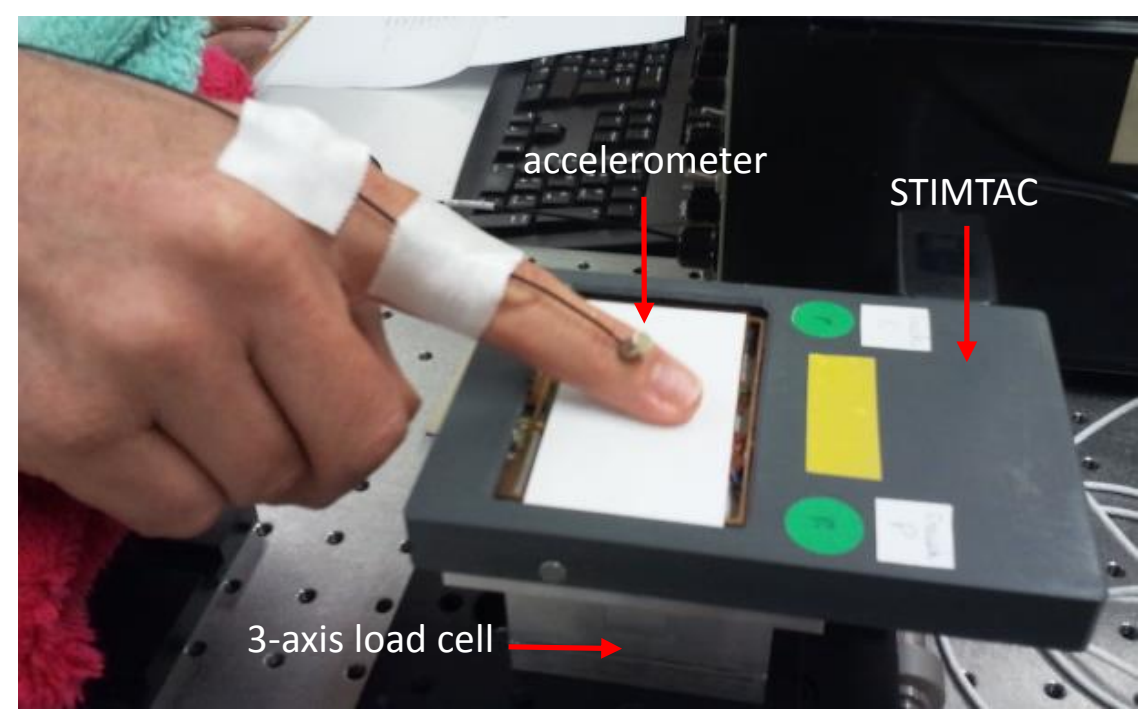

b) 
Figure 3

\section{Go signal}

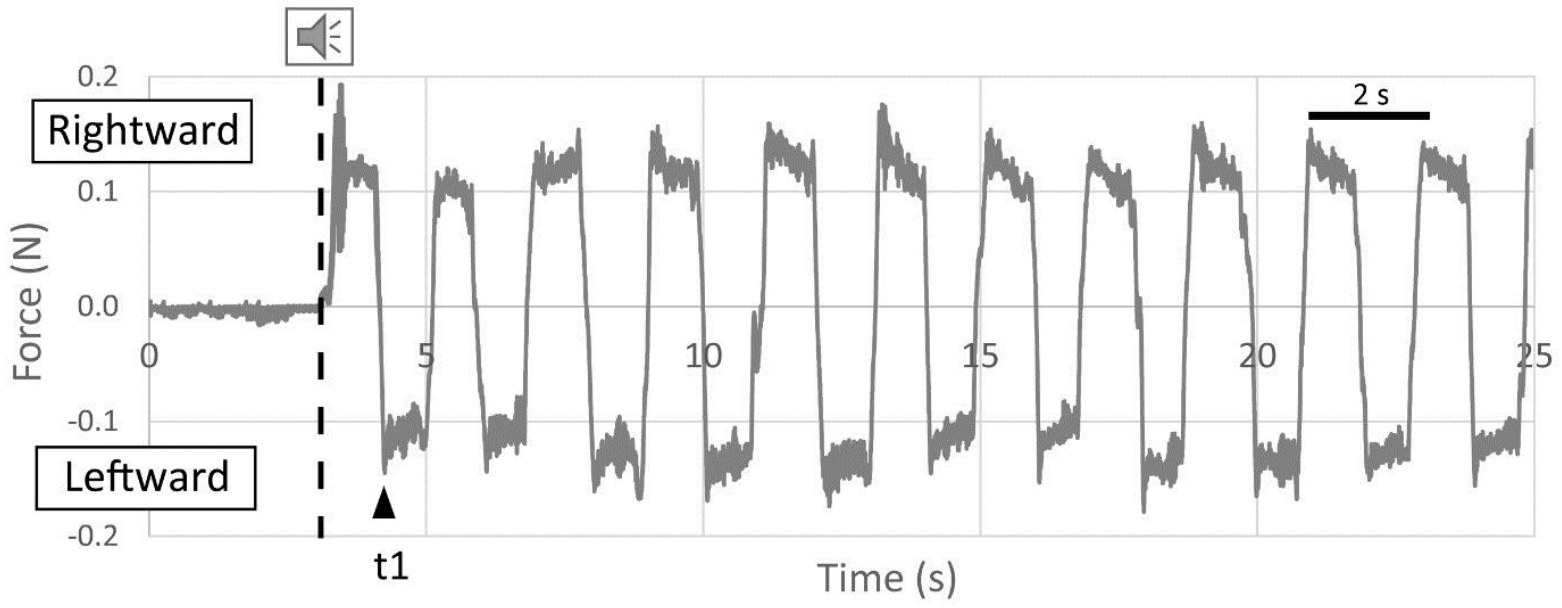


Figure 4

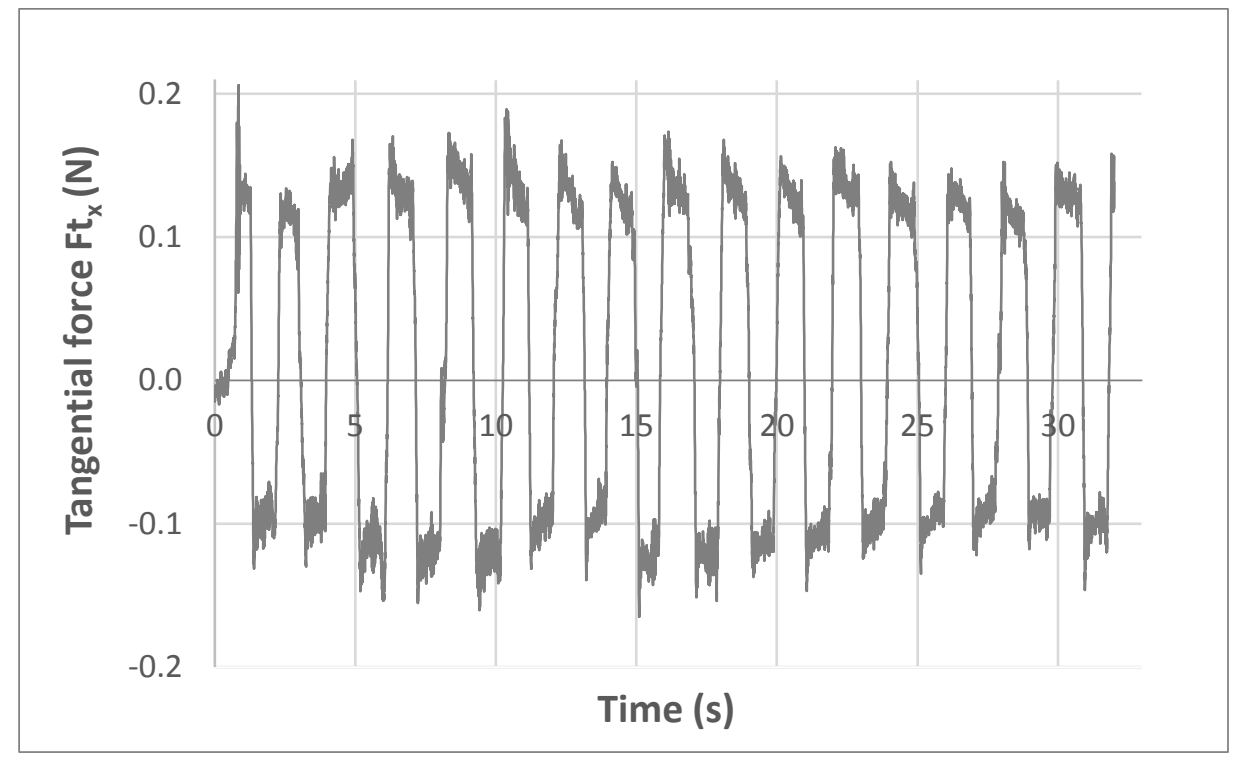

a)

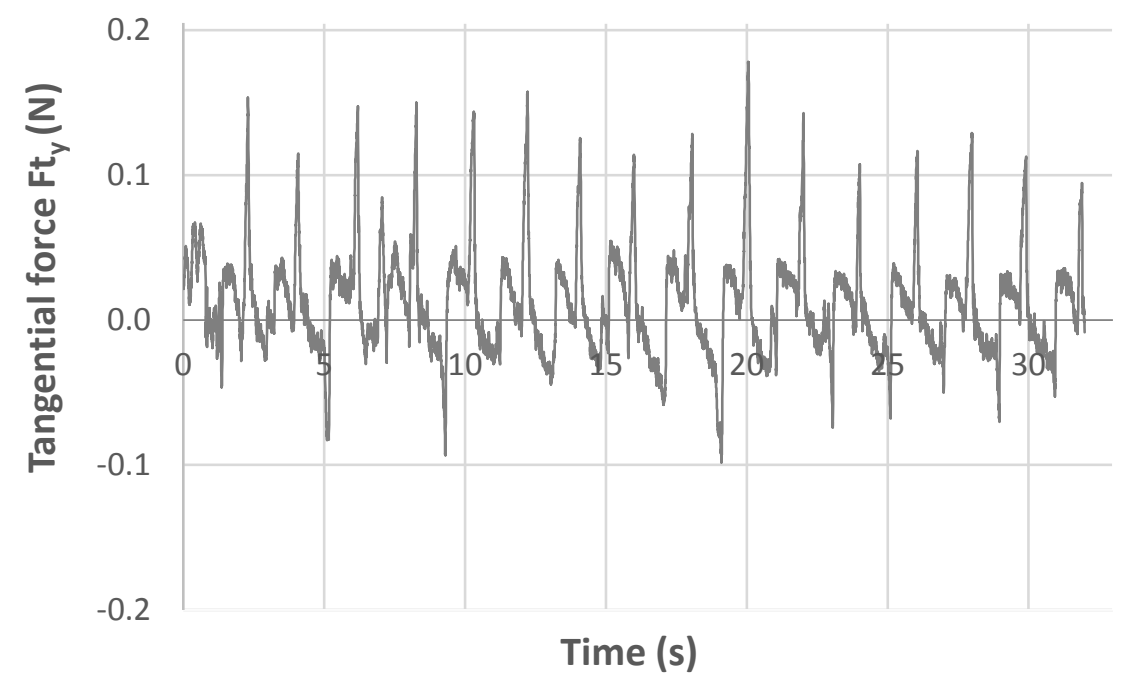

b) 


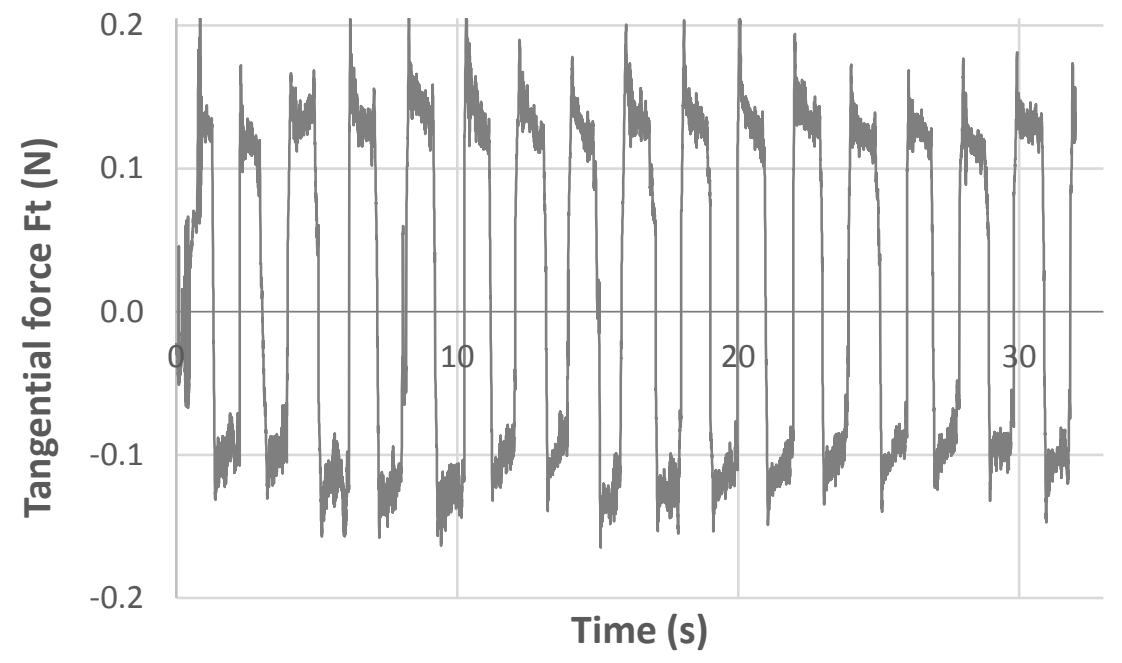

c)

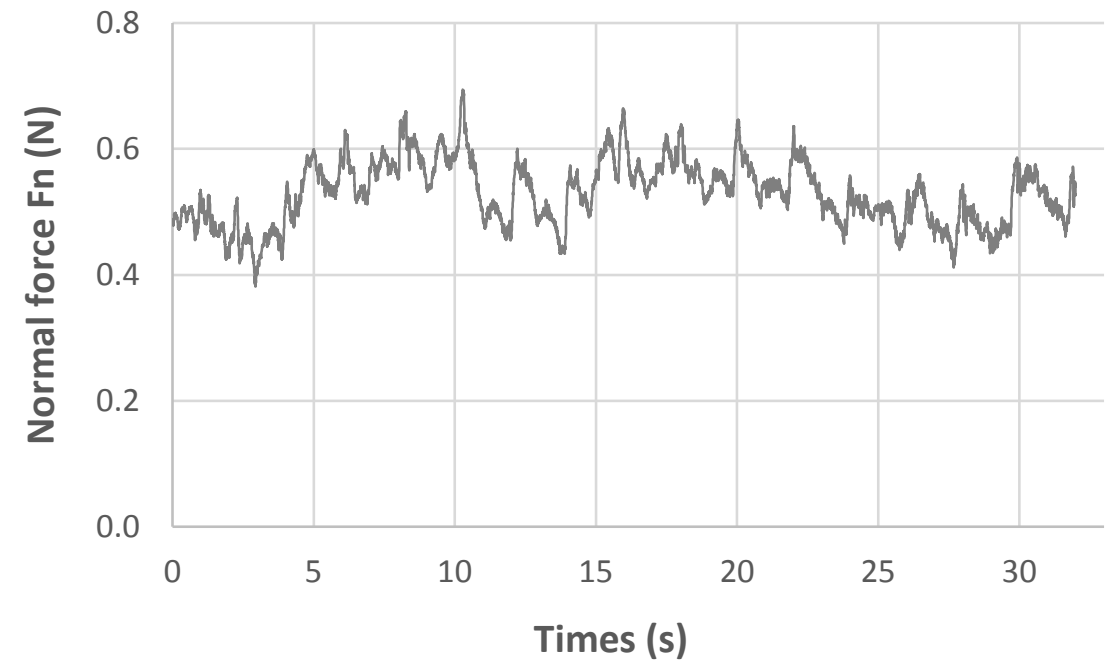

d) 


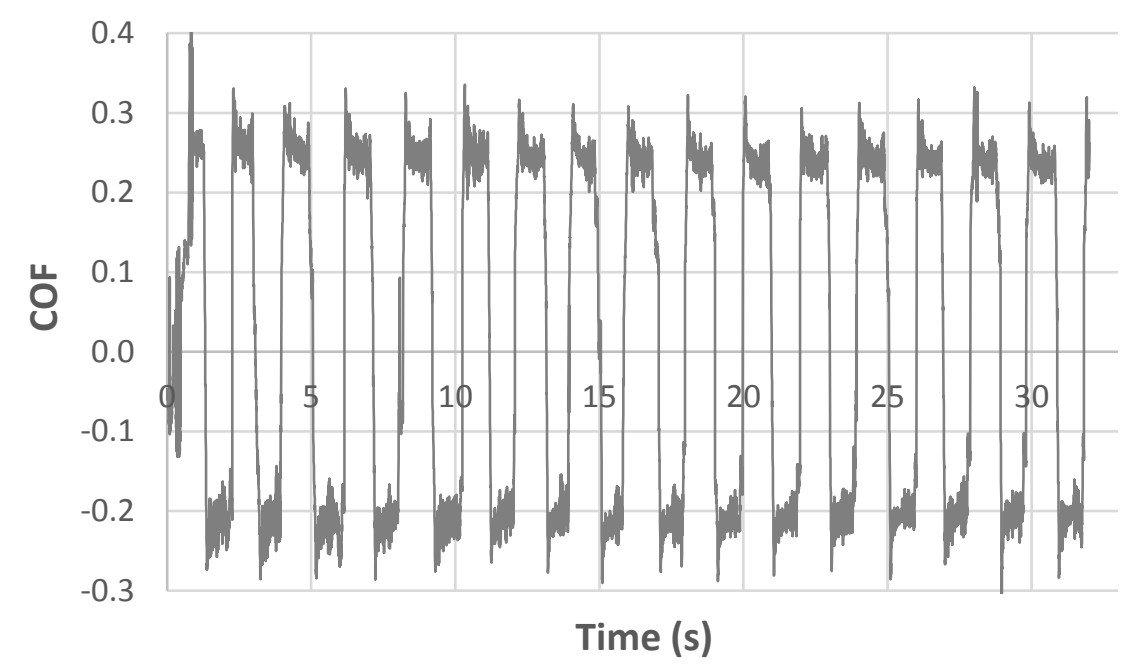

e)

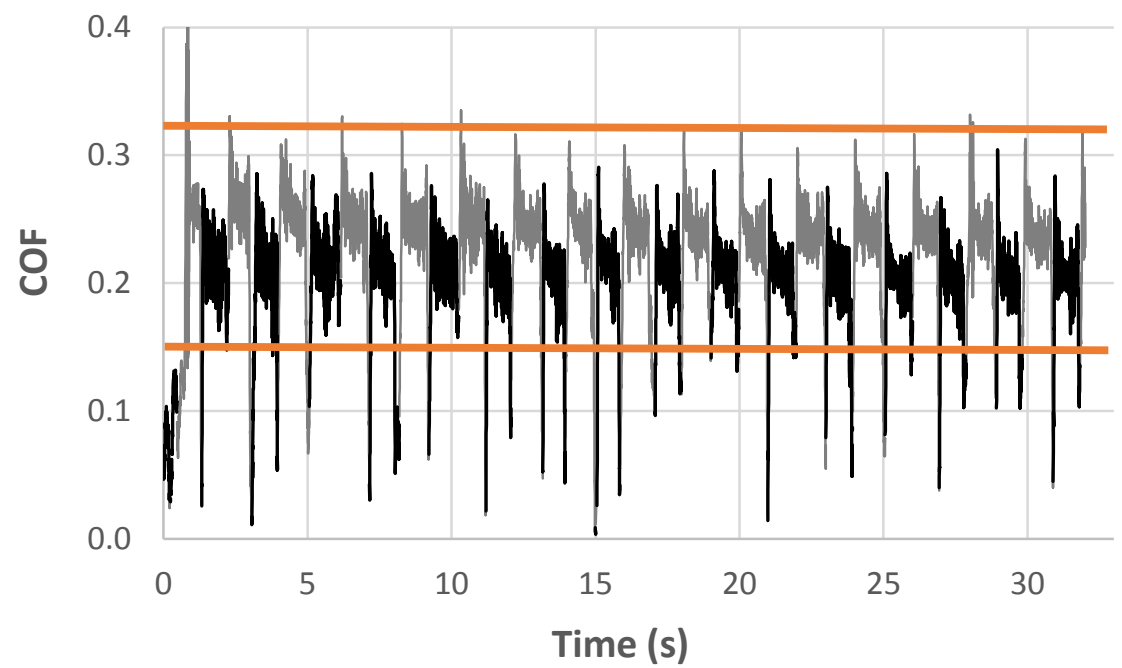

f) 


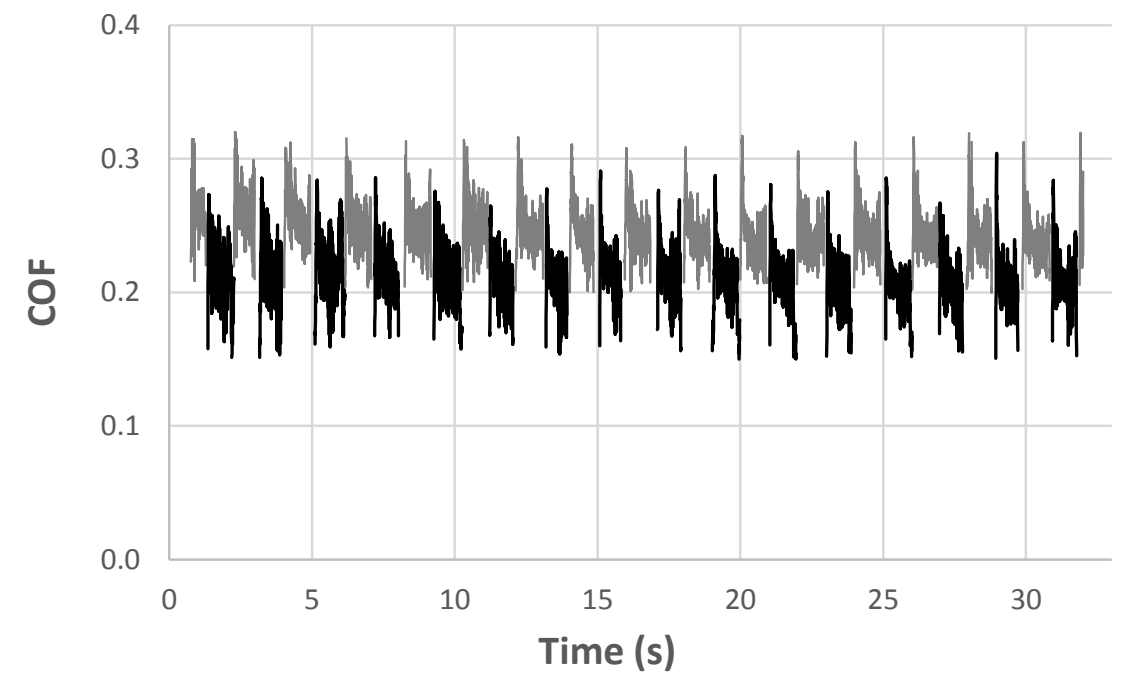

g) 
Figure 5

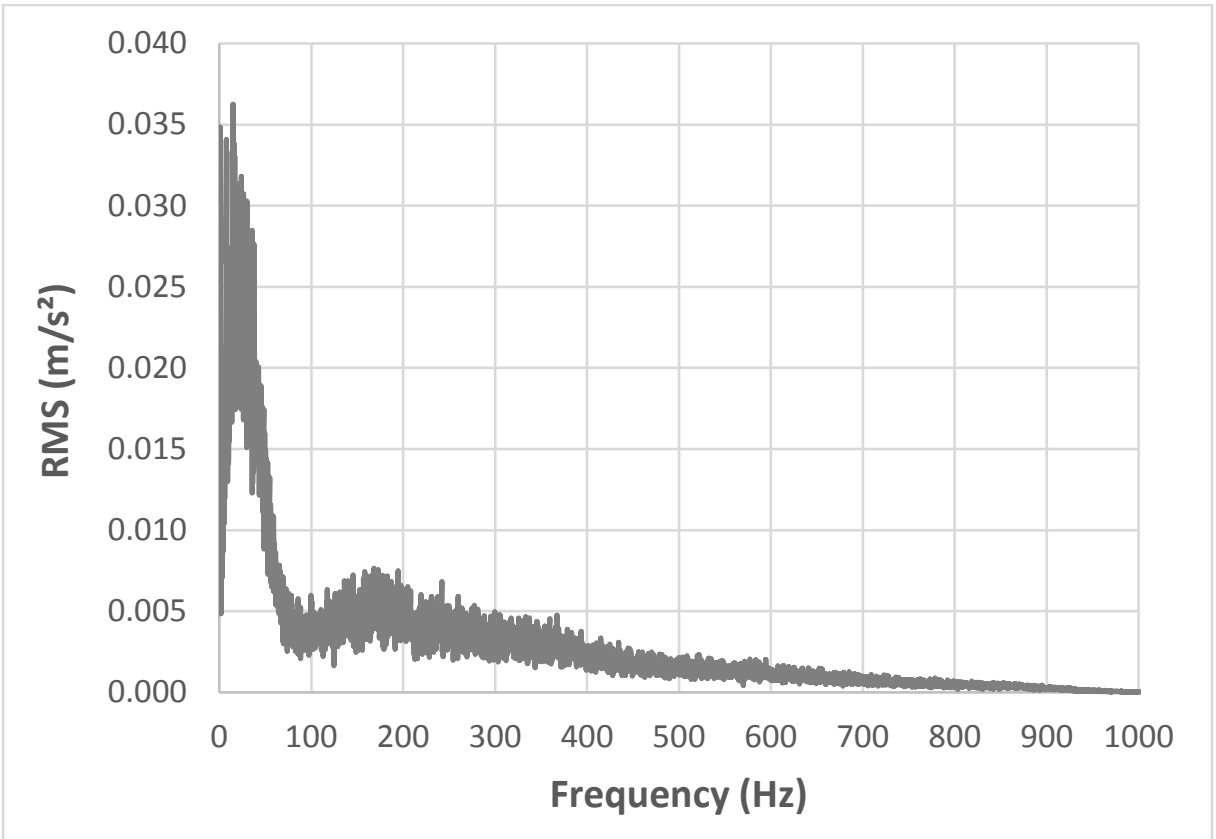

a)

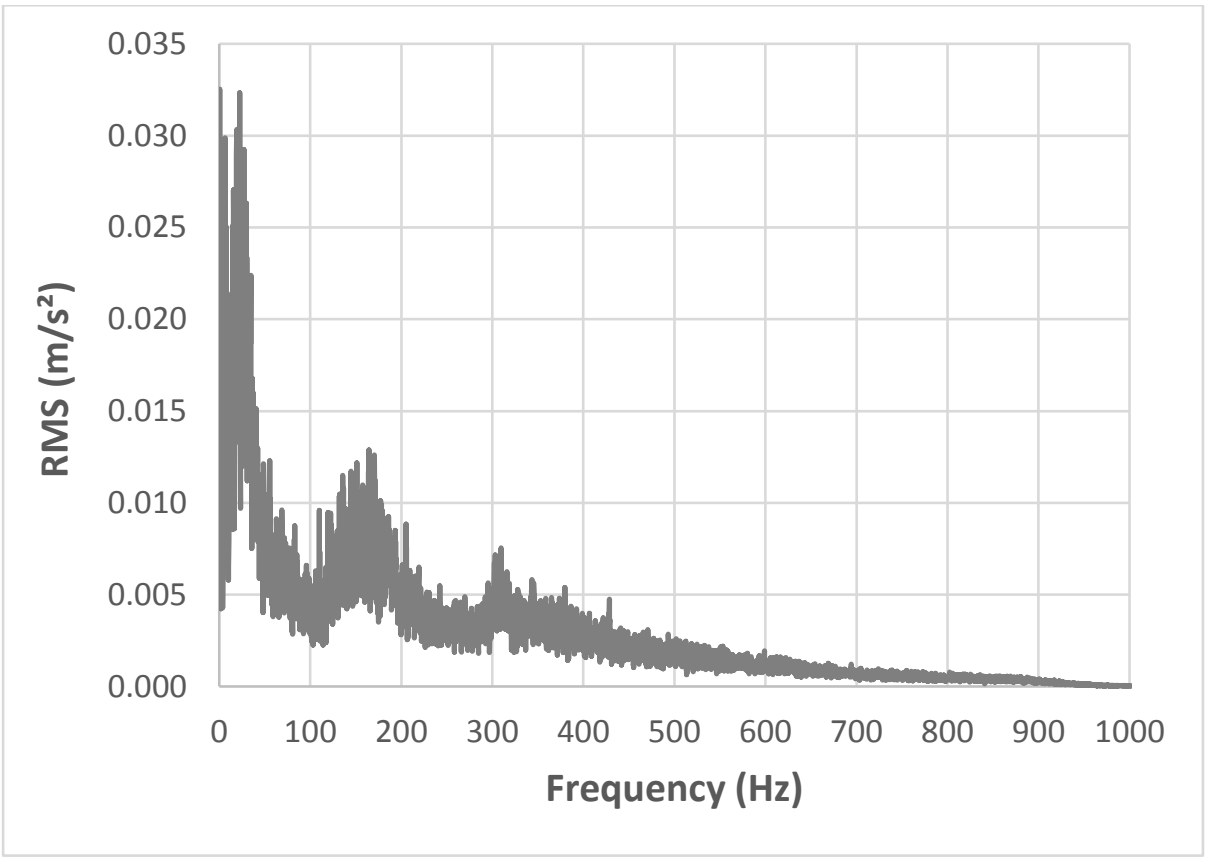

b) 
Figure 6

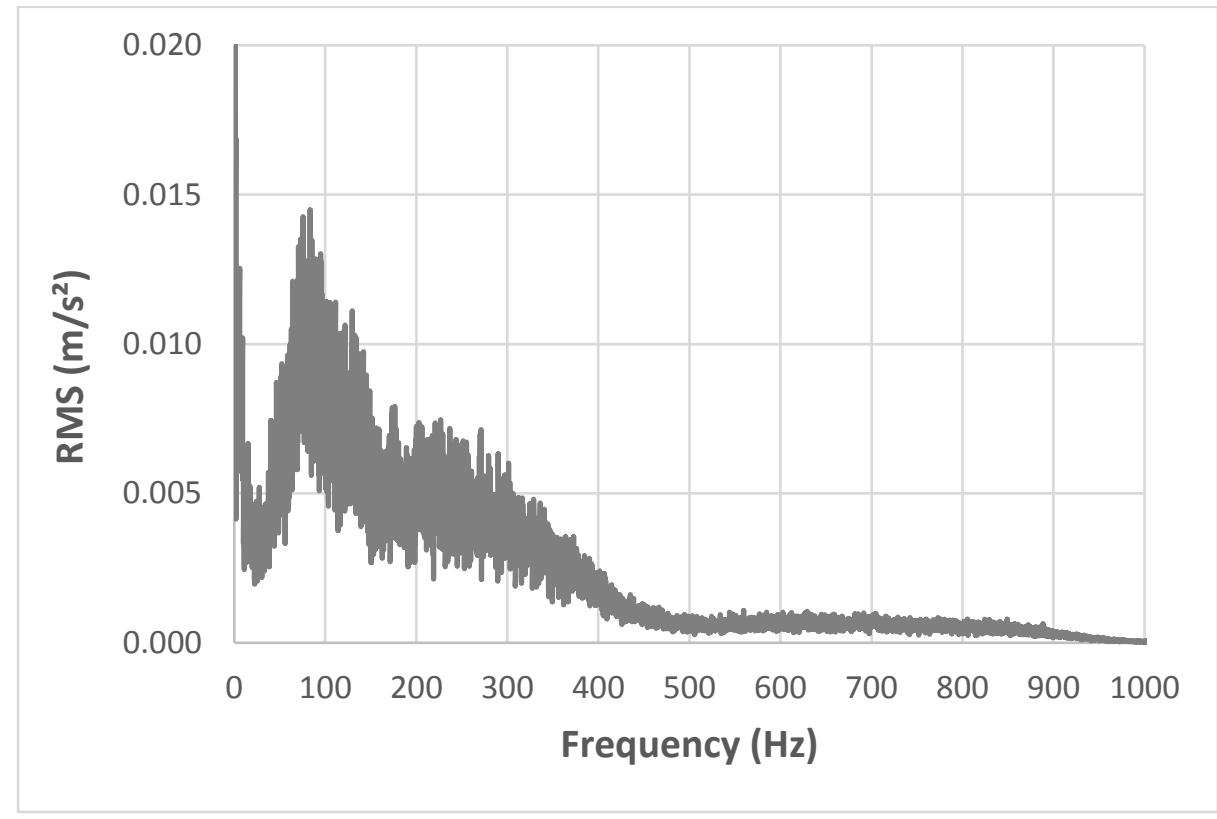

a)

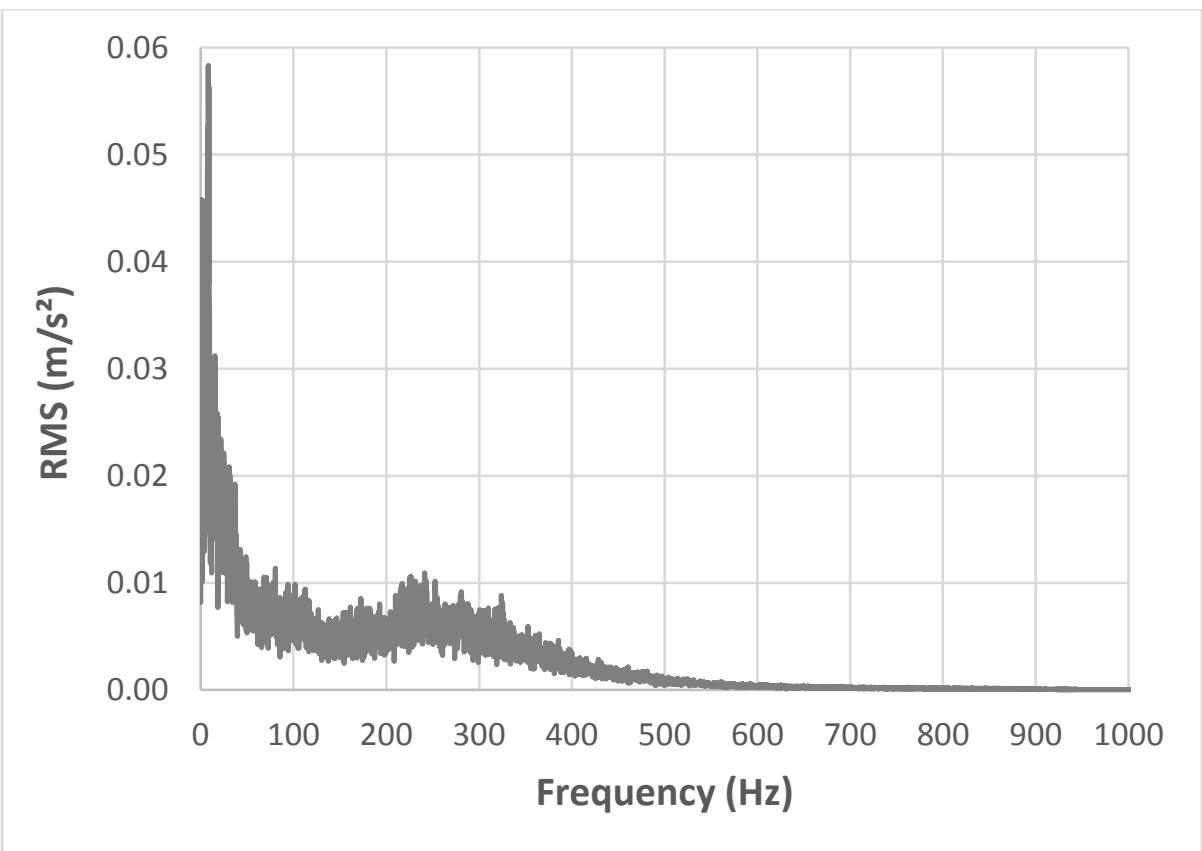

b) 


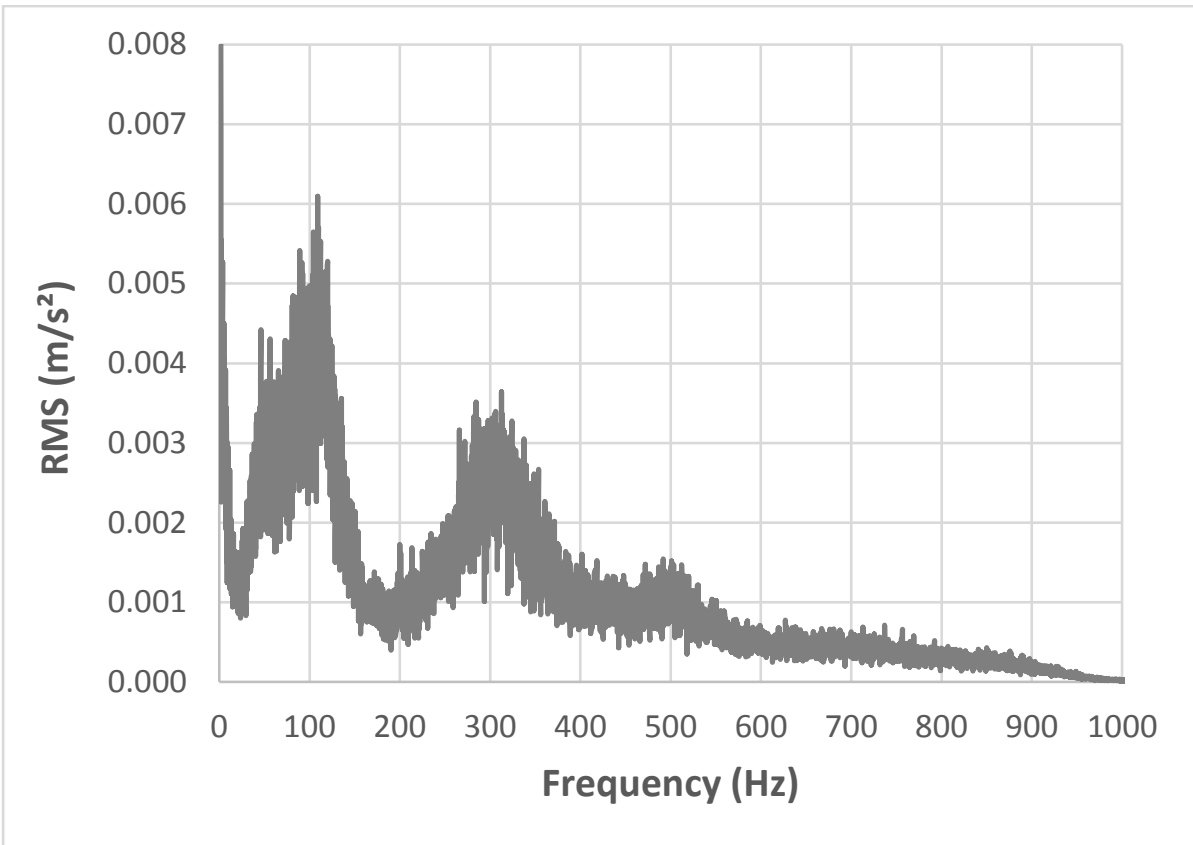

c) 
Figure 7

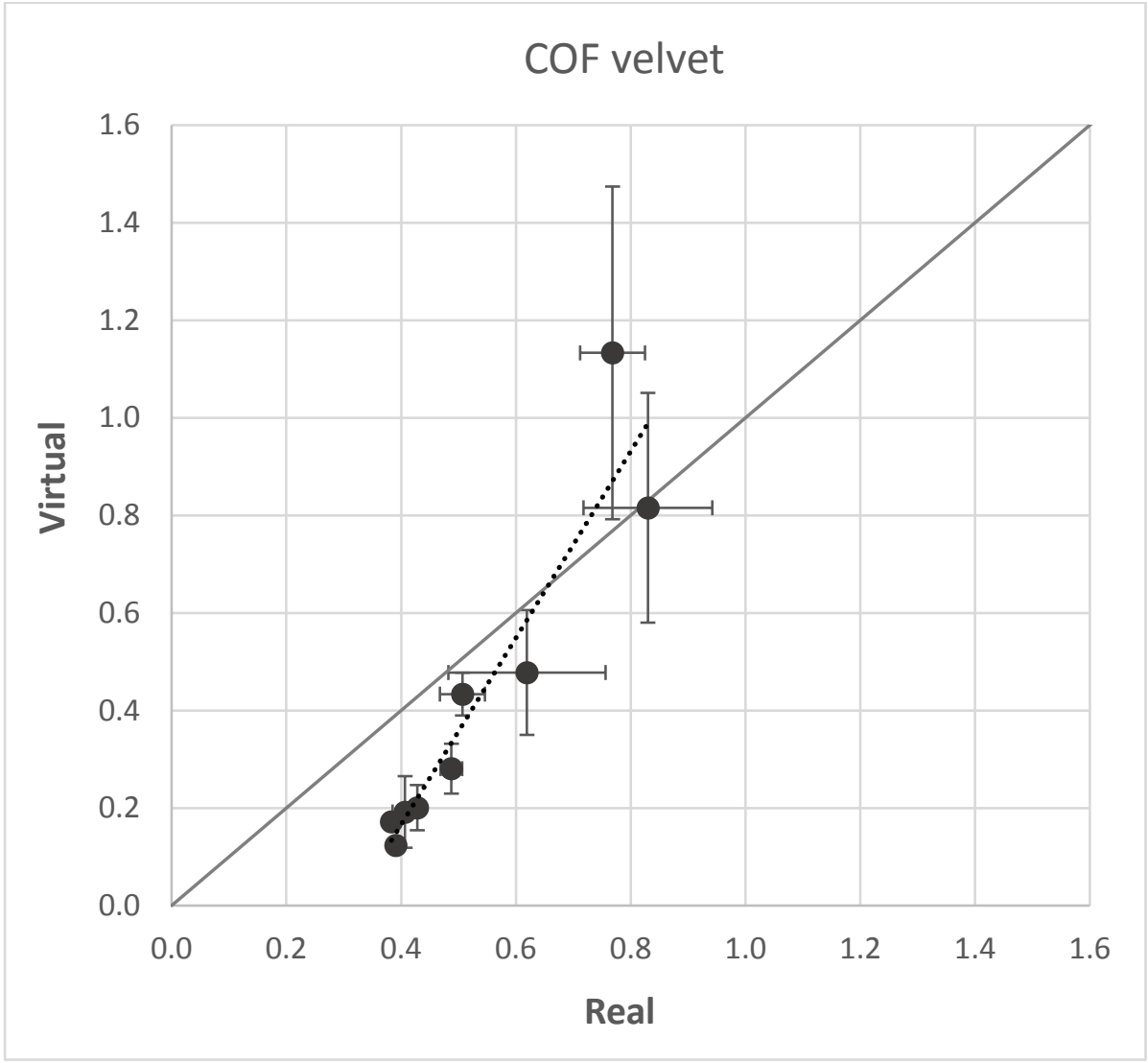


Figure 8

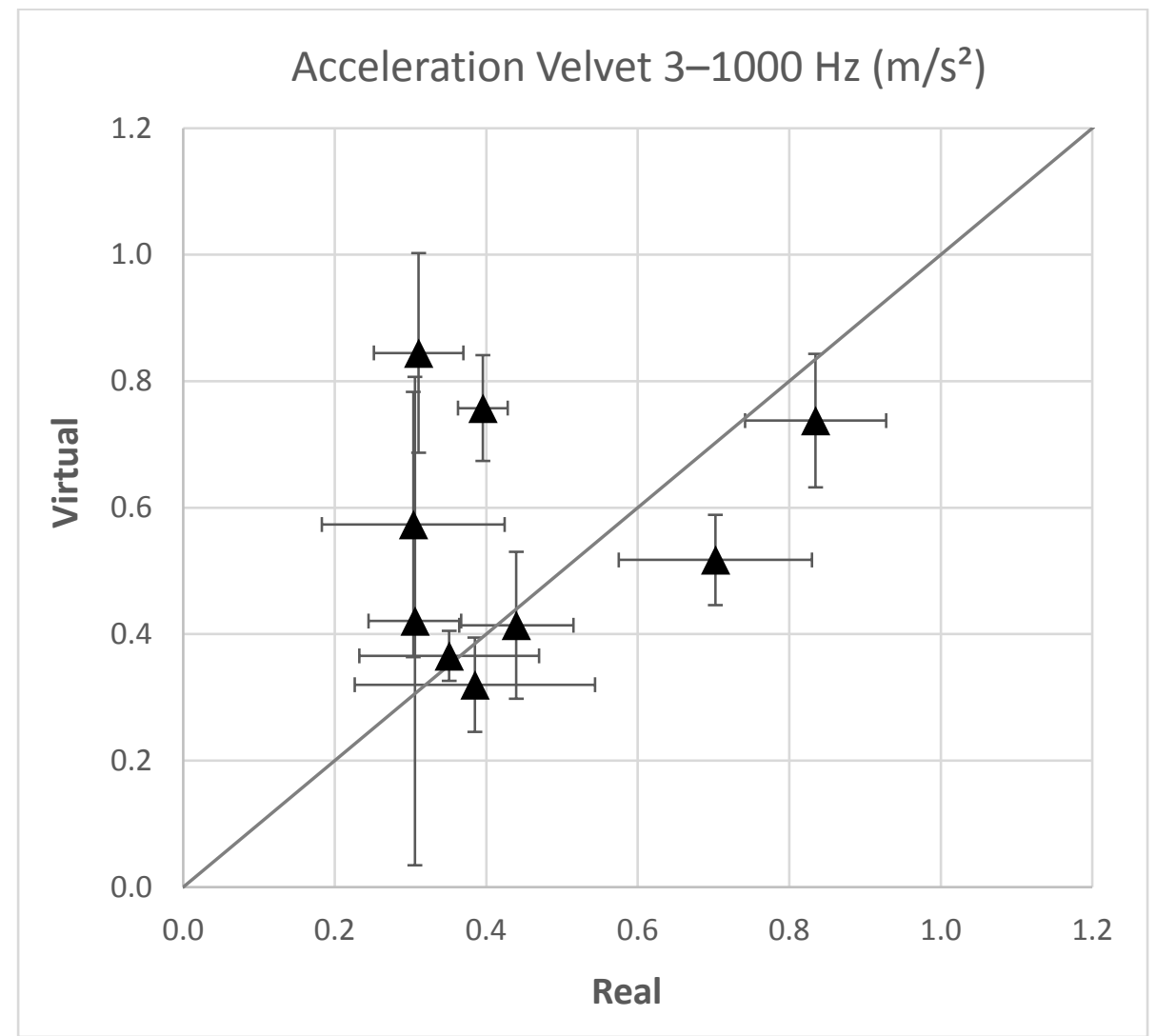

a) 


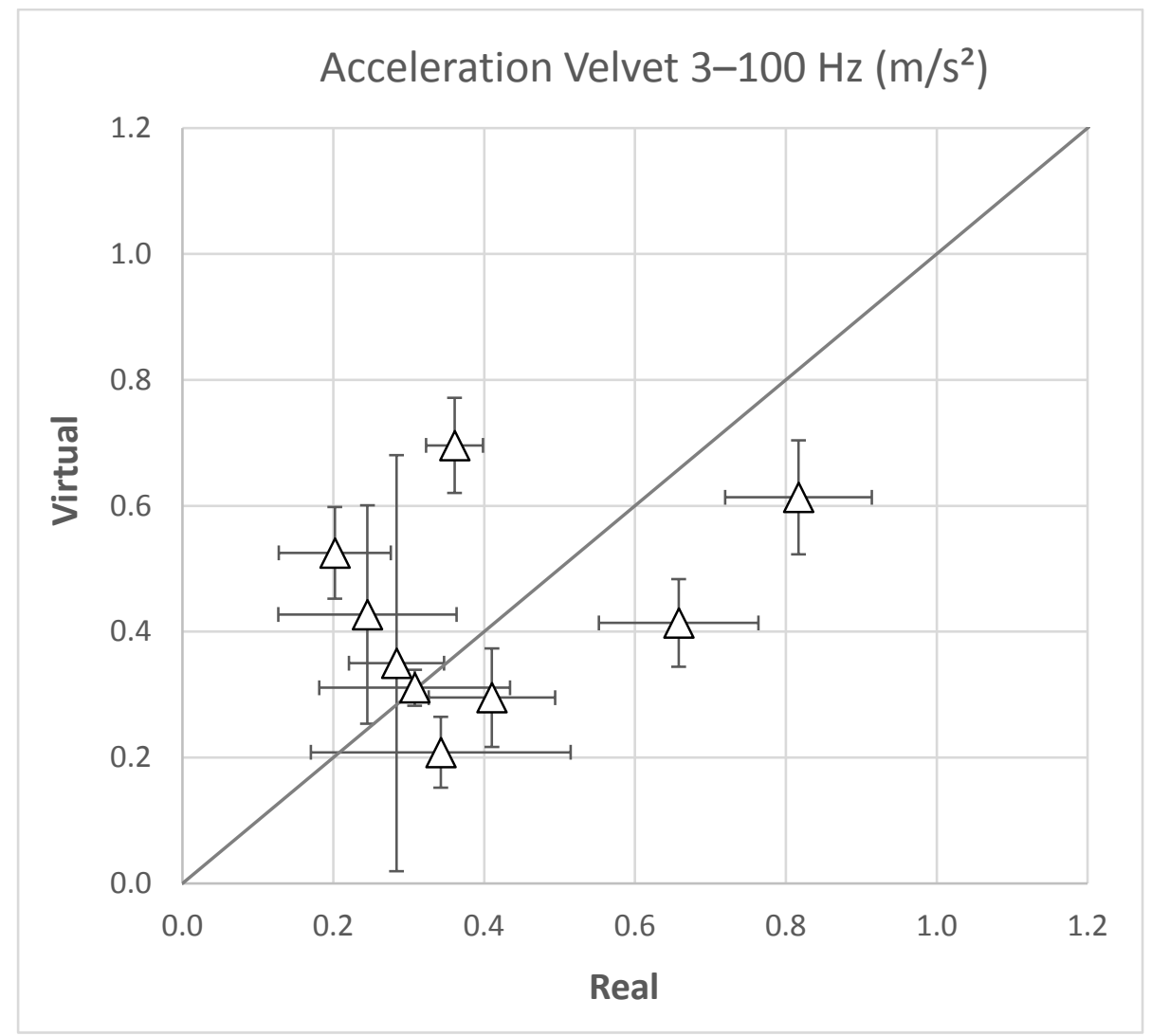

b)

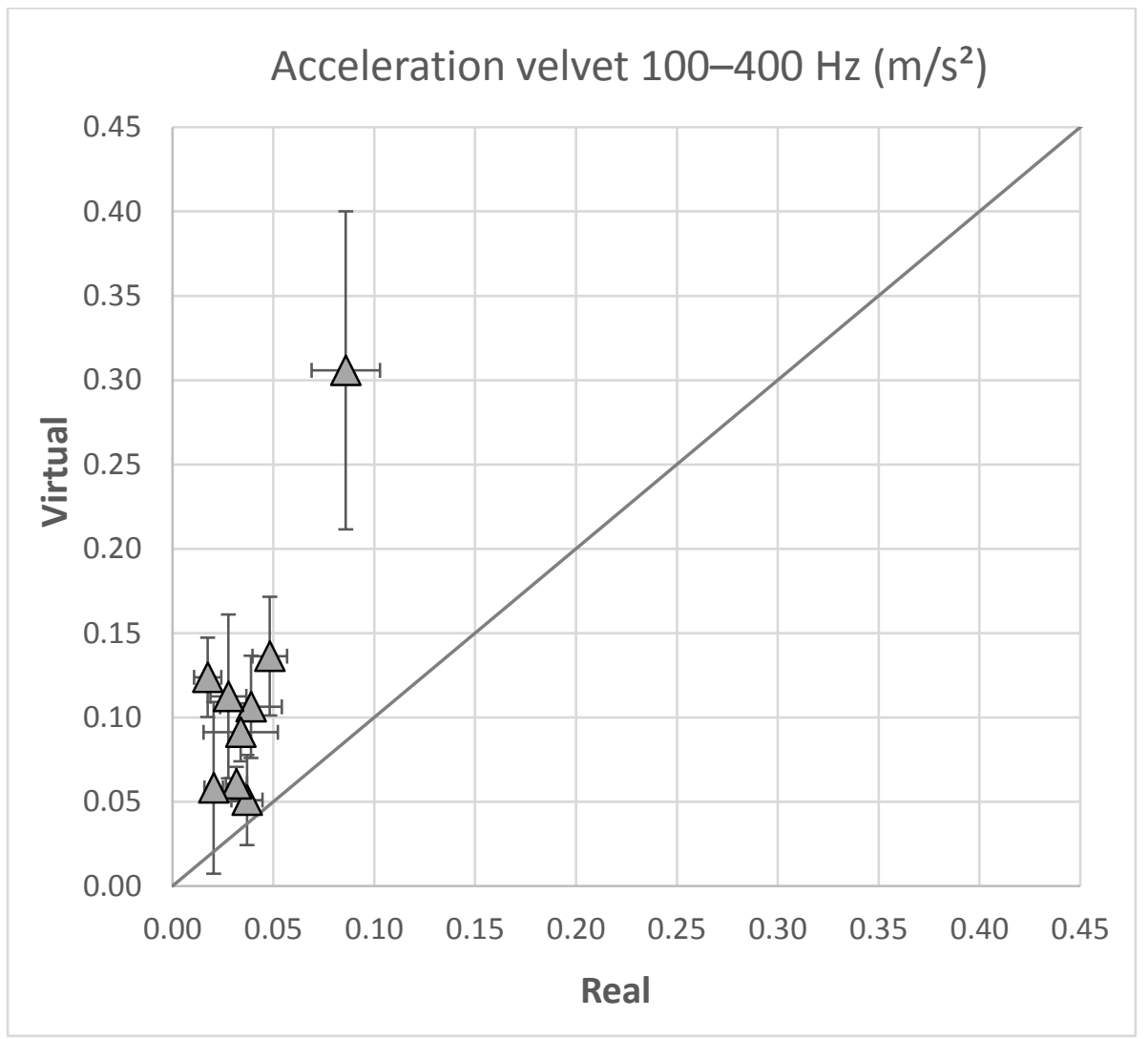

c) 
Figure 9

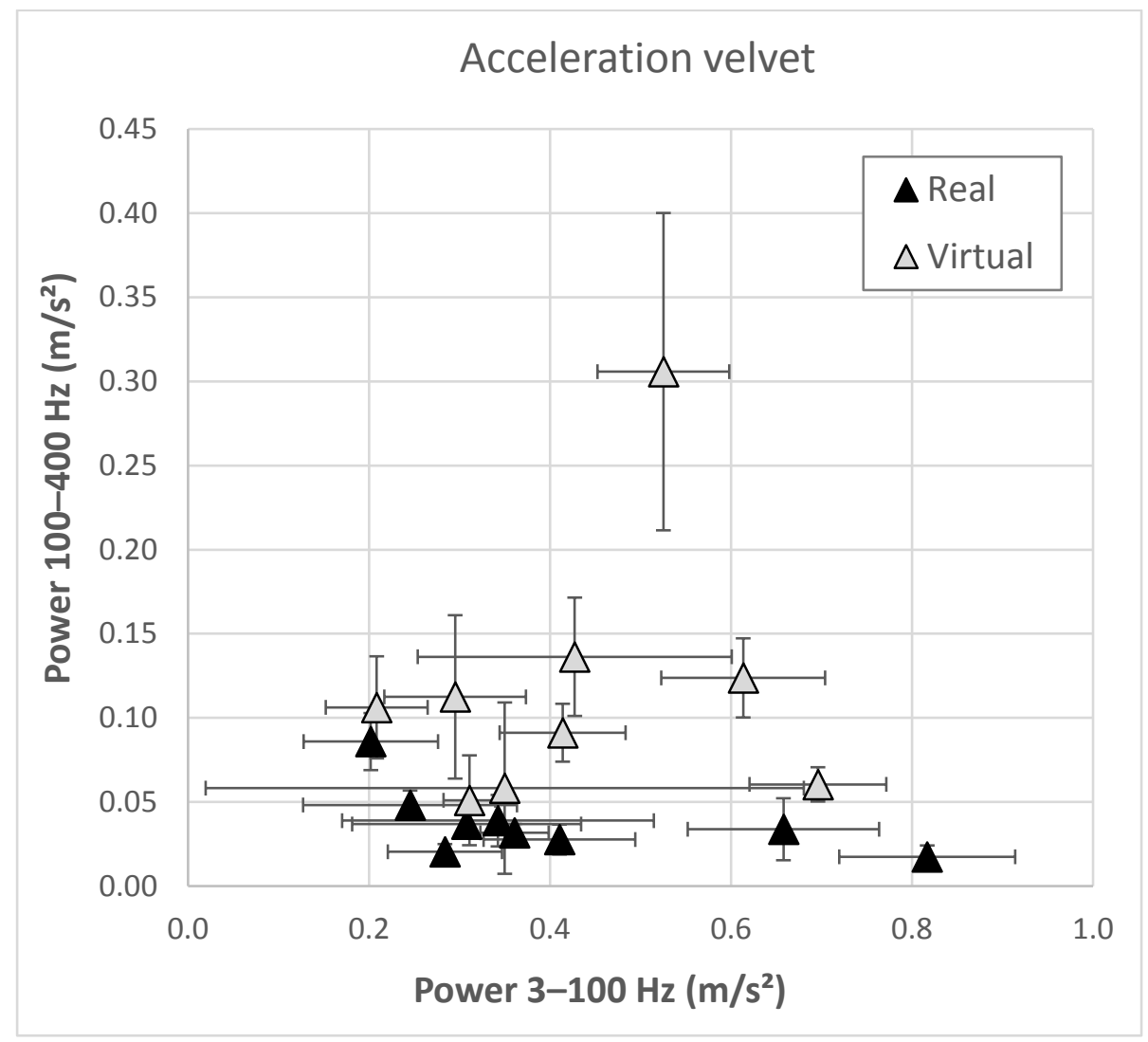


Figure 10

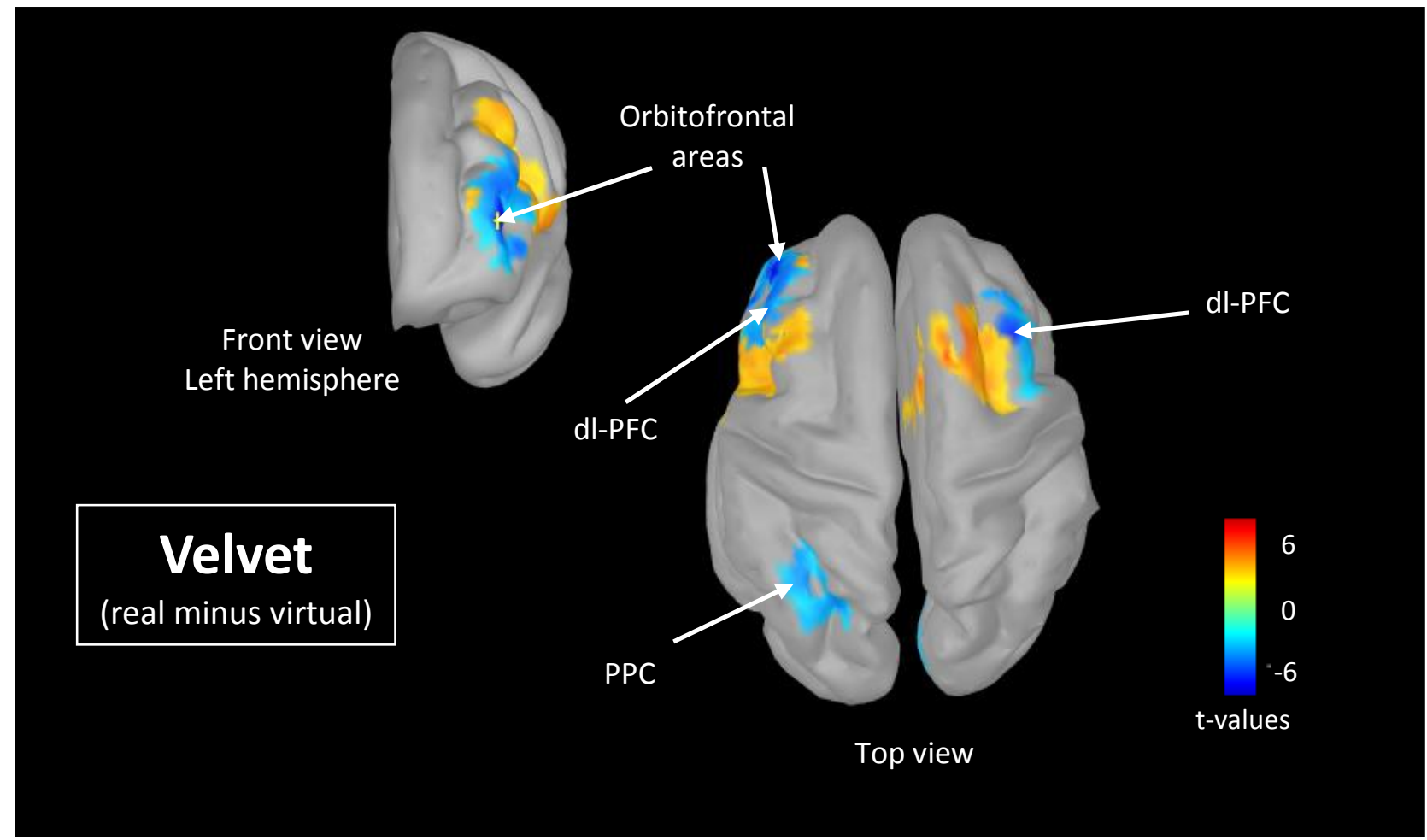


Figure 11

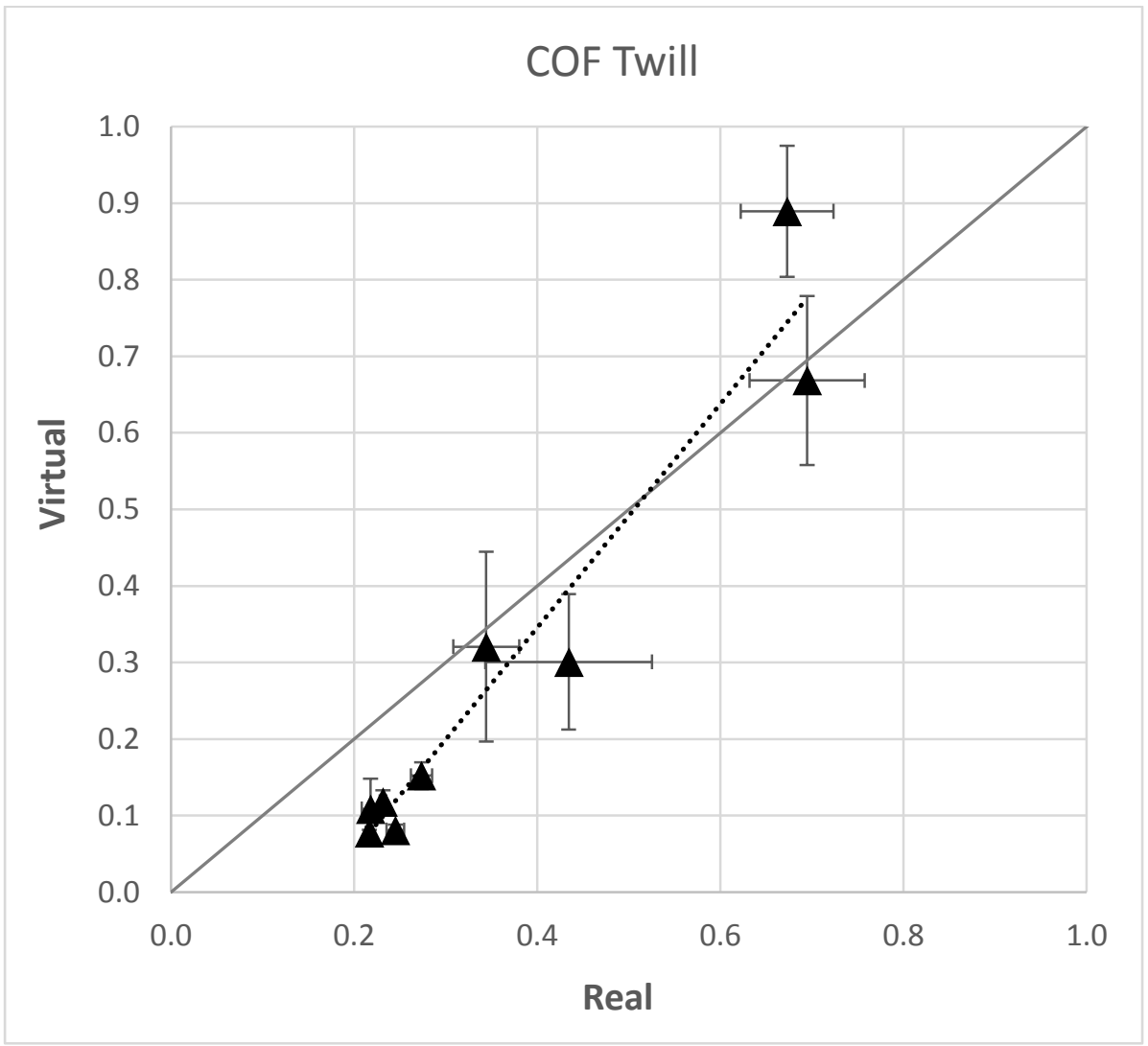


Figure 12

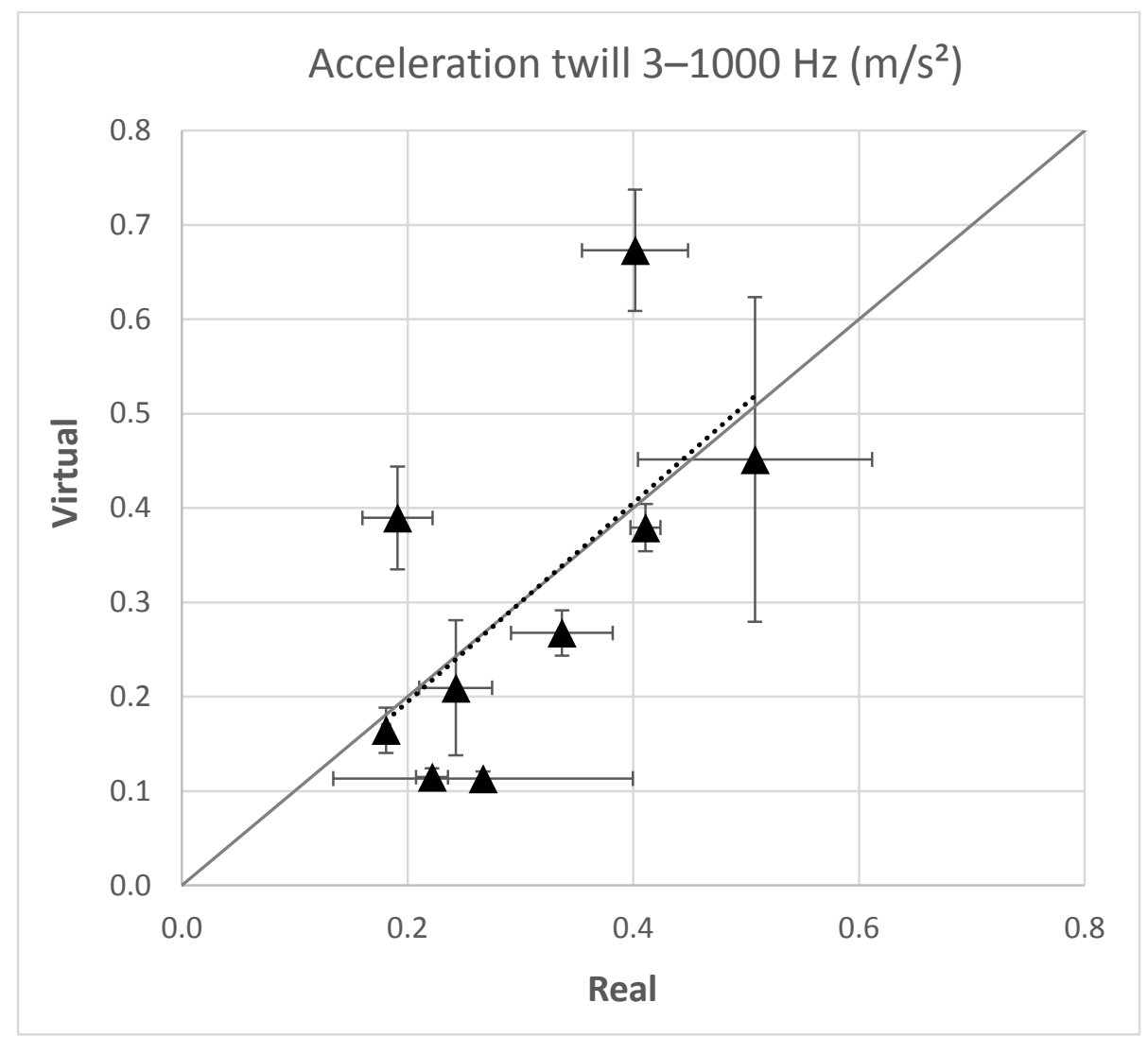

a) 


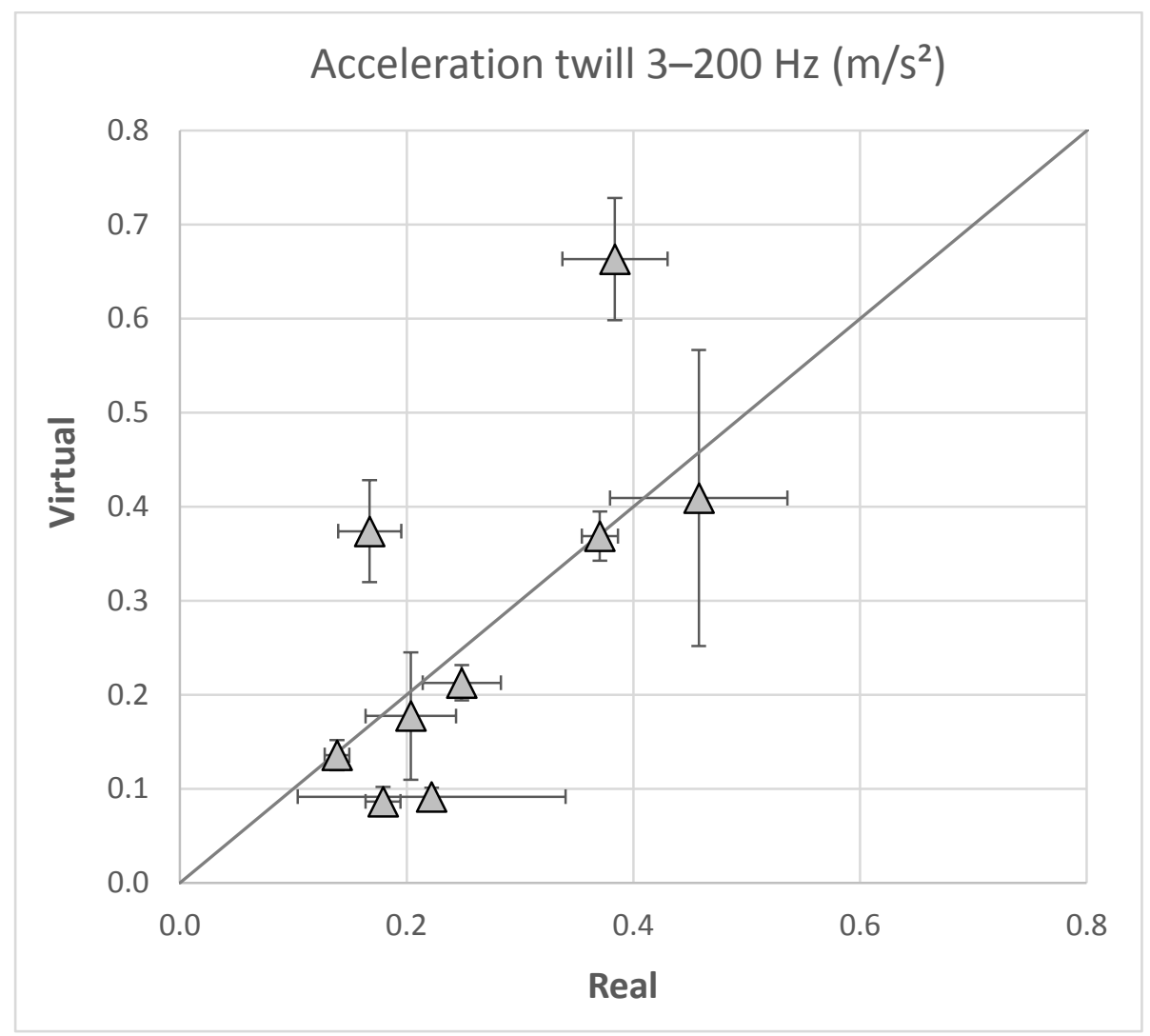

b)

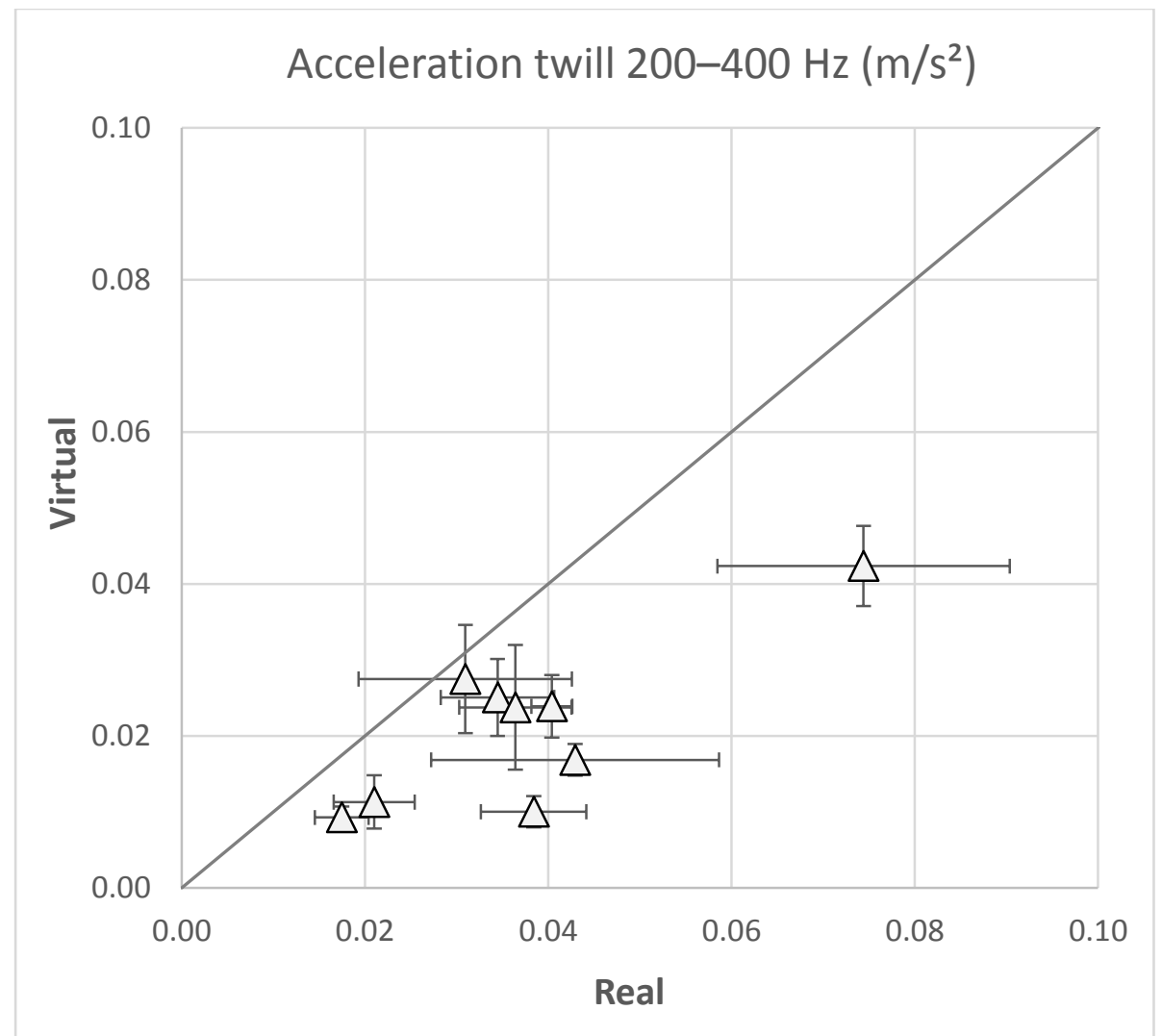

c) 
Figure 13

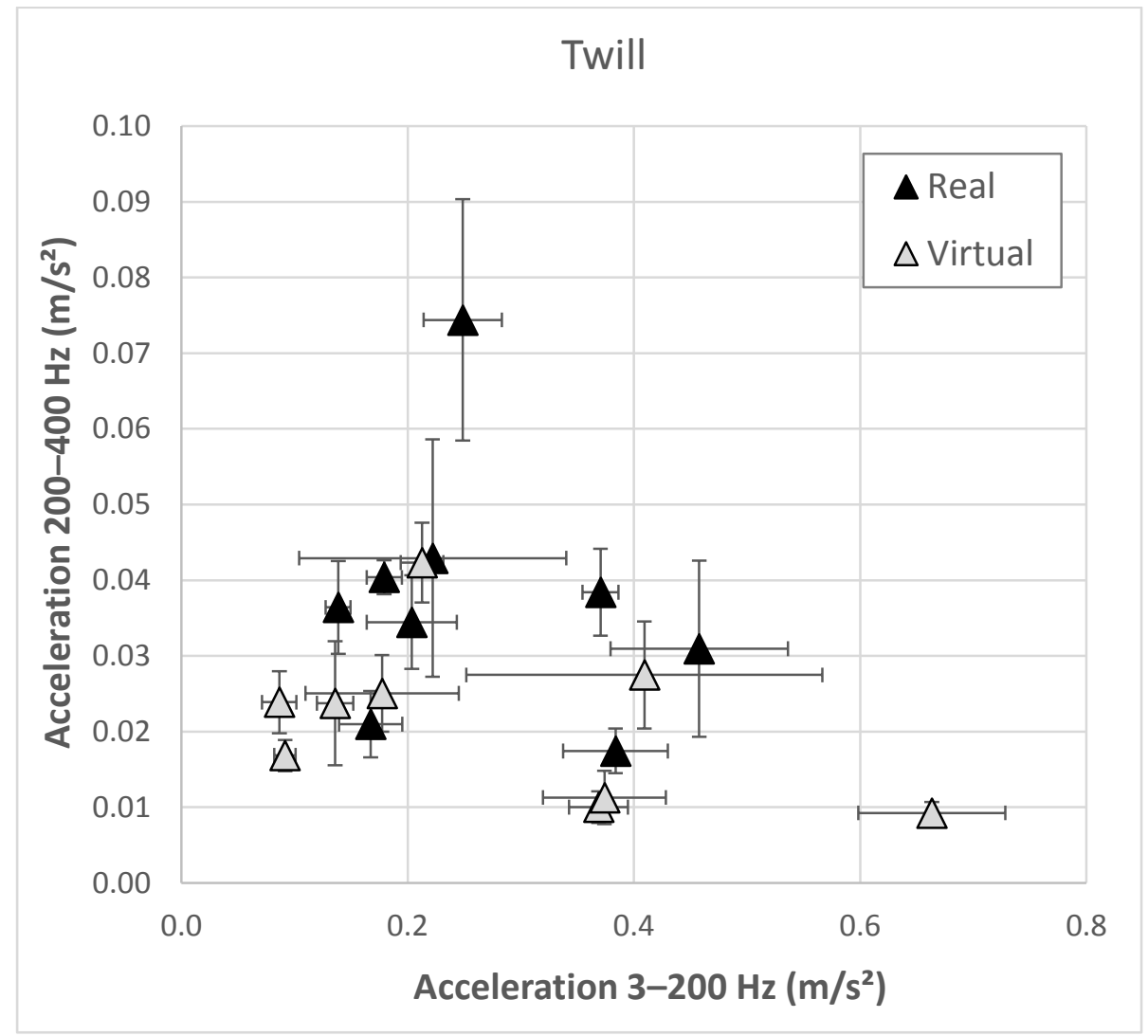


Figure 14

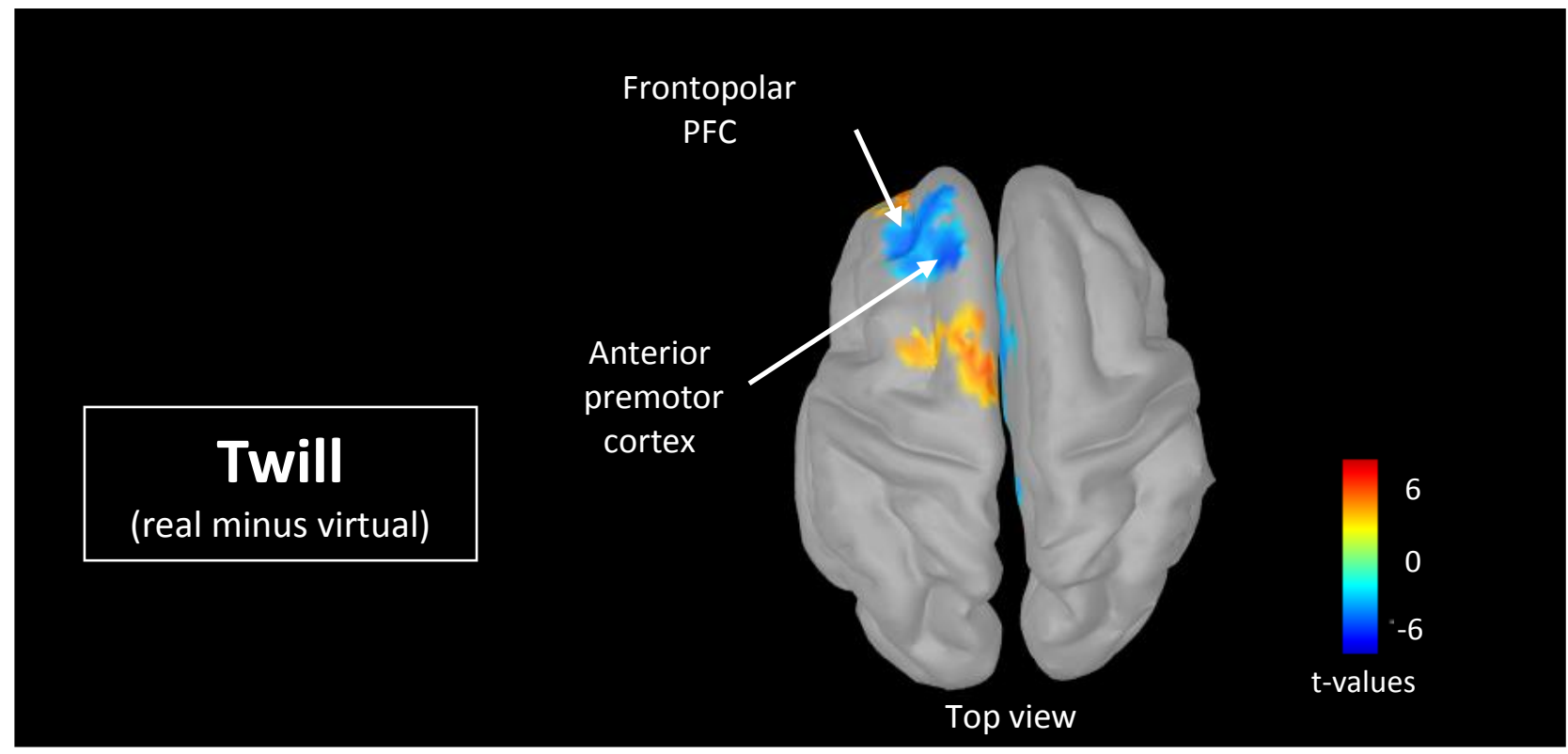


Table 1

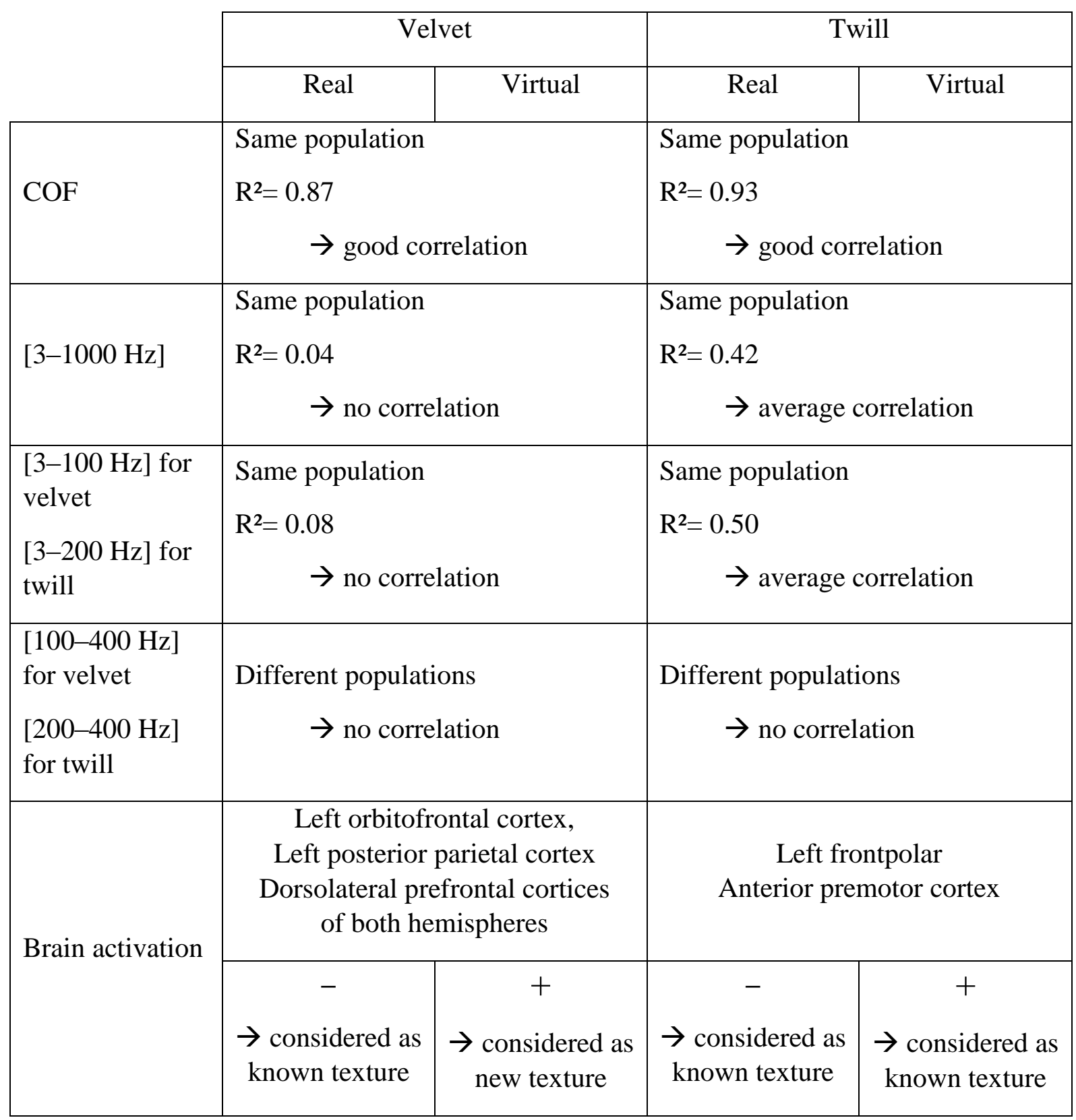

